\title{
Microencapsulation for the Therapeutic Delivery of Drugs, Live Mammalian and Bacterial Cells, and Other Biopharmaceutics: Current Status and Future Directions
}

\author{
Catherine Tomaro-Duchesneau, ${ }^{1}$ Shyamali Saha, ${ }^{1,2}$ Meenakshi Malhotra, ${ }^{1}$ \\ Imen Kahouli, ${ }^{1,3}$ and Satya Prakash ${ }^{1}$ \\ ${ }^{1}$ Biomedical Technology and Cell Therapy Research Laboratory, Departments of Biomedical Engineering and Physiology and \\ Artificial Cells and Organs Research Center, Faculty of Medicine, McGill University, 3775 University Street, \\ Montreal, QC, Canada H3A 2B4 \\ ${ }^{2}$ Faculty of Dentistry, McGill University, 3775 University Street, Montreal, QC, Canada H3A $2 B 4$ \\ ${ }^{3}$ Department of Experimental Medicine, McGill University, 3775 University Street, Montreal, QC, Canada H3A 2B4
}

Correspondence should be addressed to Satya Prakash; satya.prakash@mcgill.ca

Received 23 July 2012; Accepted 15 October 2012

Academic Editor: Anna Wesolowska

Copyright ( 2013 Catherine Tomaro-Duchesneau et al. This is an open access article distributed under the Creative Commons Attribution License, which permits unrestricted use, distribution, and reproduction in any medium, provided the original work is properly cited.

\begin{abstract}
Microencapsulation is a technology that has shown significant promise in biotherapeutics, and other applications. It has been proven useful in the immobilization of drugs, live mammalian and bacterial cells and other cells, and other biopharmaceutics molecules, as it can provide material structuration, protection of the enclosed product, and controlled release of the encapsulated contents, all of which can ensure efficient and safe therapeutic effects. This paper is a comprehensive review of microencapsulation and its latest developments in the field. It provides a comprehensive overview of the technology and primary goals of microencapsulation and discusses various processes and techniques involved in microencapsulation including physical, chemical, physicochemical, and other methods involved. It also summarizes the state-of-the-art successes of microencapsulation, specifically with regard to the encapsulation of microorganisms, mammalian cells, drugs, and other biopharmaceutics in various diseases. The limitations and future directions of microencapsulation technologies are also discussed.
\end{abstract}

\section{Introduction}

Microencapsulation has gained importance in the fields of cell and tissue engineering, as well as in the development of drug formulations and oral delivery systems. There are a number of already marketed microencapsulated products for the delivery of pharmaceutics [1]. The term microencapsulation, in this work, encompasses the terms microcapsules, microparticles, microspheres, and microemulsions. Generally, the term microsphere is employed for a homogeneous structure made of one continuous phase, and the term microcapsule is used for a reservoir-like structure with a well-defined core and envelope/coat. There exist a variety of microcapsules which can differ in size, composition, and function. The characteristics of the microcapsules ultimately depend on the final goal of the encapsulated product, as they can be used to entrap all sorts of substances: solids, liquids, drugs, proteins, bacterial cells, stem cells, and so forth. With such a range of substances that can be entrapped, one can conclude that microcapsules can have an assortment of objectives and applications, whether for drug delivery, enzyme retrieval, artificial cell and artificial tissue delivery, and delivery of microorganisms.

This paper provides an up-to-date review of microencapsulation and its latest developments. It provides a comprehensive overview of microencapsulation technology, the primary goals of microencapsulation, and the processes and techniques involved. This includes the physical, chemical, physicochemical, and other methods. Specifically, this paper comprehensively discusses the use of microencapsulated 
TABLE 1: Methods for microencapsulation.

\begin{tabular}{l}
\hline Chemical methods \\
\hline Solvent evaporation \\
Interfacial cross-linking \\
Interfacial polycondensation/interfacial condensation \\
polymerization \\
In situ polymerization \\
Matrix polymerization \\
\hline Physical methods \\
\hline Spray drying \\
Pan coating \\
Fluid-bed coating \\
Centrifugal extrusion \\
Vibrating nozzle/vibrating-jet \\
Spinning disk/rotational suspension separation \\
\hline Physicochemical methods \\
\hline Ionotropic gelation \\
Polyelectrolyte complexation \\
Phase separation/coacervation (simple and complex) \\
Supercritical fluid technology
\end{tabular}

microorganisms in renal diseases, cardiovascular diseases, colorectal cancer, inflammatory bowel disease, and others. Microencapsulation for mammalian cells is described for diabetes, hepatic diseases, parathyroid insufficiency, anemia, cancer, and neurodegenerative diseases. The use of microencapsulated drugs and other pharmaceutics focuses on hormone therapy, gastrointestinal disorders, diabetes, pulmonary diseases, periodontitis, and hypertension. The limitations and future directions of microencapsulation are also discussed.

\section{Goals of Microencapsulation}

Microencapsulation can be used to achieve a number of objectives. Some goals of microencapsulation include material structuration, protection of the enclosed product, and controlled release of the encapsulated contents, as shown in Figure 1. Microcapsules can provide structuration to compounds that are normally difficult to administer due to factors such as the material's insolubility, volatility, reactivity, hygroscopicity, and physical state [93]. Microcapsules may also serve the role of protecting the encapsulated contents to prevent the degradation of the product due to external environmental factors such as oxygen, light, heat, and humidity which could destroy any labile compound. Protection by microcapsules may also be required when orally administering a therapeutic, due to exposure to the harsh conditions of the upper gastrointestinal tract (GIT). In addition, the host's immune system would quickly lead to the implanted cells' rejection and undesired side effects if the cells are recognized as foreign. Immunoprotection and immunoisolation may be achieved by a microcapsule, important for the in vivo delivery and implantation of mammalian cells, such as stem cells, for tissue and cell engineering applications. The capability of microcapsules to serve the purpose of immunoprotection has been well demonstrated in a number of disease contexts, including type 1 diabetes, Parkinson's disease, Alzheimer's disease, cancers, and other disorders [48, 94-97]. Microcapsules may also serve to permit the controlled release of the encapsulated contents, which can be regulated by chemical, physical, and mechanical factors. A controlled release can permit a longer and more efficient therapeutic effect of an enzymatic by-product, which, otherwise, may have a limited half-life in vivo. It may also regulate the release of the encapsulated product at the desired time, rate, dose, and site of action.

\section{Microencapsulation Methods}

There are a number of techniques that can be used to fabricate microcapsules, depending on the desired characteristics and applications of the final microcapsule formulation. These techniques can be broadly categorised into chemical, physical and physicochemical methods, as highlighted in Table 1.

3.1. Chemical Methods of Microencapsulation. Chemical methods of microencapsulation include solvent evaporation, interfacial cross-linking, interfacial polycondensation, in situ polymerization, and matrix polymerization. Solvent evaporation is a technique used by many companies for the production of microcapsules, especially for drug encapsulation, as the method often requires heat [98]. The process necessitates that the core material be dissolved/dispersed in the coating solution followed by agitation in the liquid vehicle to obtain the desired microcapsule size [98]. This mixture is then heated to evaporate the solvent, followed by temperature reduction.

The microencapsulation method of interfacial polycondensation, also termed interfacial condensation polymerization, was pioneered by Chang [99]. The method involves the Schotten-Baumann reaction between an acid chloride and a compound containing an active hydrogen atom [100]. This reaction involves two polymeric reactants in a polycondensation that meet and form thin walls at the microcapsule interface [101]. The method of interfacial cross-linking originated from that of interfacial polycondensation and also involves the Schotten-Baumann reaction. The process involves a bifunctional monomer containing active hydrogen atoms which, during encapsulation, are replaced by a biopolymer, such as a protein [102]. At the interface of the emulsion, the membrane of the microcapsule is formed by the reaction of an acid chloride with the functional groups of the protein. A carbohydrate or starch may also be added for an increased modulation of biodegradability and other physical properties [103].

In situ and matrix polymerizations are methods used in a number of microencapsulation processes for coating of the microcapsule. In situ polymerization is characterized by the fact that the reactants are not included in the core material, but, rather, polymerize together to form the particle 


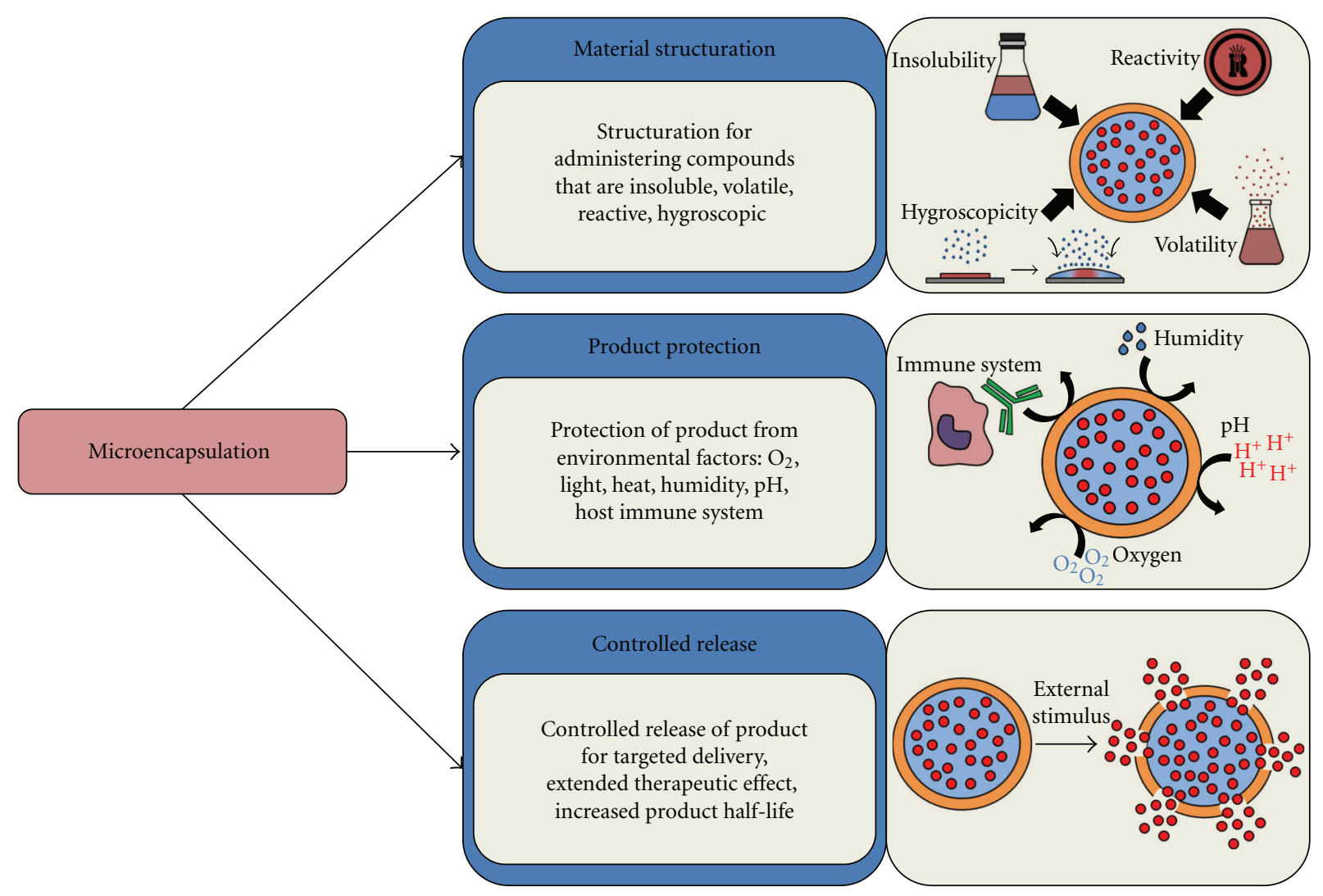

FIGURE 1: The main biopharmaceutical goals of microencapsulation: microencapsulation can be used to achieve material structuration, therapeutic product protection, and targeted delivery and/or controlled release of the encapsulated biotherapeutics.

surface [104]. Solidification and stabilization can then be achieved by a number of methods. Matrix polymerization, on the other hand, involves the embedding of the core material in a polymeric matrix during particle formation. This is the case in spray drying, using heat as a physical method of polymerization. In terms of a chemical method of polymerization, this can be achieved using matrices such as epoxy [104].

3.2. Physical Methods of Microencapsulation. Physical methods include spray drying, fluid-bed/pan coating, centrifugal extrusion, vibrating nozzle, and spinning disk microencapsulation. For spray drying, an emulsion is prepared by the dispersion of an oil core material or water-soluble active ingredient into a concentrated coating material. The emulsion can then be atomized into a spray of droplets using a rotating disc and a short exposure in a heated compartment to allow water to evaporate, yielding dry microcapsules. Spray drying is an economical method that can allow for the encapsulation of labile materials such as proteins and microorganisms [21, 105].

Fluid-bed coating is a microencapsulation technique used extensively to encapsulate pharmaceuticals into coated particles or tablets [106]. It is a variation of the pan coating method, one of the oldest industrial procedures, where solid particles are mixed with a dry coating material that is heated to surround the particle cores [107]. Solid particles (or liquids absorbed into porous solids) are suspended on a jet of air followed by the application of a coating material using a liquid spray. The resulting shells are solidified by cooling or solvent vaporization, and the process is repeated until the microcapsule walls are of the desired thickness. The Wurster fluid bed system, where the spray nozzle is located below the particle fluidized bed, is one commonly used system for this type of particle coating [108].

Centrifugal extrusion is an easy-to-scale-up microencapsulation technique that involves the use of a spinning extrusion head made up of concentric nozzles [109]. The microcapsule core and coating materials, both immiscible with each other, are pushed through the concentric nozzles forming a flow that splits into droplets following clearing of the nozzle. Depending on the materials used during microencapsulation, solidification of the droplets can then be undertaken by cooling or gelation methods.

Vibrating nozzle, also termed vibrating-jet, is a popular microencapsulation method [110,111]. The liquid material to be encapsulated is extruded through a nozzle at a specific flow rate, forming a laminar jet. Unlike the centrifugal extrusion technique which relies on natural and irregular disturbances leading to irregular size and shape, this method uses a permanent sinusoidal force at determined frequencies, forming microcapsules of uniform distribution [112]. As in centrifugal extrusion, the solidification of the microcapsules can be undertaken using cooling or gelation. 
Spinning disk, also termed rotational suspension separation, is another physical technique for microencapsulation. A mixture is formed with the material for the internal core of the microcapsule and the liquid microcapsule coating material. This dispersion is then flowed onto a turning disk, causing the microcapsules (and coating material shells) to be thrown off of the rim of the disk followed by solidification using cooling or gelation techniques. Purification is then performed to isolate the microcapsules from coating material particles.

3.3. Physicochemical Methods of Microencapsulation. Physicochemical encapsulation techniques involve ionotropic gelation, polyelectrolyte complexation, coacervation, and supercritical fluid technology. Ionotropic gelation relies on the ability of polyelectrolytes to cross-link when in the presence of counterions, leading to their gelation [113]. This process has been extensively studied using natural polyelectrolytes such as alginate $[114,115]$, chitosan [116], carboxymethyl cellulose [117], and gellan gum [118]. Gelated beads are produced by the addition of polymeric drops, containing the anionic therapeutic to be encapsulated, into an aqueous solution of polyvalent cations [113]. Ionic cross-linking forms a three-dimensional lattice due to the diffusion of cations into the polymeric drops. Polyelectrolyte complexation, the addition of polycations or polyelectrolytes to the surface of the beads, can be used to further improve the mechanical strength and permeability of the gelated beads.

Coacervation, also termed phase separation, is one of the oldest and most widely used methods of encapsulation that relies on polymer-polymer incompatibility [119]. This technique can be classified into simple and complex coacervation. Simple coacervation involves the addition of a salt or alcohol into the polymeric mixture, promoting the liquidliquid phase separation and the formation of coacervate polymer droplets [120]. Complex coacervation occurs in the presence of two phases and modification of the aqueous phase $\mathrm{pH}$. This leads to the formation of a membrane at the interface of the coacervate polymer droplets. Subsequently, the membrane can be solidified and further stabilized by polymer cross-linking.

Supercritical fluid technology has recently gained pharmaceutical interest for the formation of particles that are monodispersed with the capability to form nanosized particles [121, 122]. Supercritical fluids can form particles by rapid depressurization or by exceeding the saturation point of a solute by dilution, as well as a combination of both of these processes [122]. Because these reactions occur quicker in supercritical fluids, as compared to liquids, nucleation and spinodal decomposition over crystal growth are promoted, leading to the generation of small particles.

In summary, microencapsulation has strong therapeutic potential, and using the previously methods, microcapsules can be suitably designed for a specific purpose. The following section discusses the use of microencapsulation for the delivery of microorganisms, mammalian cells and drugs, and other pharmaceutics. The following section comprehensively discusses the disease applications where microencapsulation can be used.

\section{Microencapsulated Microorganisms}

Microencapsulation has been widely used for the encapsulation and immobilization of microorganisms [114]. Bacterial cell encapsulation is a process that can occur naturally as bacteria proliferate and produce exopolysaccharides, highmolecular-weight polymers composed of sugar residues. The exopolysaccharide structure can act as a protective capsule and reduce the permeability and bacterial exposure to potential adverse environmental factors. Early research used microencapsulation for the immobilization of bacterial cells in the food and dairy industry, as discussed in other reviews $[123,124]$. In recent years, the microencapsulation of probiotic cells, "live microorganisms, which, when administered in adequate amounts, confer a health benefit on the host," has gained interest for the treatment of a number of gastrointestinal and other health disorders [125]. However, orally delivered probiotic cells must be delivered and remain viable through the harsh conditions of the upper GIT. Hence, microencapsulation can be used as a protection for the delivery of the cells. Research focused on microencapsulation of probiotics has proven successful in the contexts of renal failure, cardiovascular diseases, and in colon disorders, as described later.

\subsection{Microencapsulated Microbes in Renal Failure. Early} research in the field of microencapsulated microorganisms was undertaken, by Prakash and Chang, using a genetically modified Escherichia coli strain (DH5) containing a urease gene from Klebsiella aerogenes [2, 126]. The encapsulation was performed by gelation of alginate in calcium chloride, followed by coating steps with polylysine and alginate, to give rise to alginate-polylysine-alginate (APA) microcapsules containing E. coli cells. When administered orally to uremic rats, the encapsulated $E$. coli successfully lowered the levels of plasma urea and ammonia back to normal levels, as well as modulating many markers of renal failure [3]. This was the first report that recorded the use of polymeric membrane artificial cells for the oral delivery of genetically engineered organisms [3]. This research also highlighted microencapsulation as a method to isolate the delivered microorganisms through the GIT transit until excretion, eliminating safety issues associated with the delivery of microorganisms. Research was also undertaken, in vitro, with the same E. coli but using polyvinyl alcohol microcapsules which have a significantly higher mechanical strength than APA microcapsules [4, 127]. Supplemental research was also performed with Lactobacillus delbrueckii capable of removing urea, to respond to concerns of toxicity associated with the use of the genetically engineered $E$. coli strain [8].

Research by Prakash et al. provided the first research investigating the use of microencapsulated yeast cells, Saccharomyces cerevisiae, in renal failure [5]. The research group investigated the oral administration of live yeast cells in APA microcapsules in a renal failure uremic rat model [5]. The study demonstrated that the microencapsulated yeast cells were retained in the microcapsules through the GIT transit but allowed urea to diffuse through the semipermeable 
membrane of the microcapsule and were acted upon by yeast urease [5]. More importantly, a significant $18 \%$ decrease was noted for the urea levels during the 8 -week treatment period, demonstrating the efficacy of the formulation as a therapeutic for eliminating the elevated levels of metabolites present in renal failure [5].

\subsection{Microencapsulated Microbes in Hypercholesterolemia and} Cardiovascular Diseases. Microencapsulation of bacterial cells has recently gained interest for the treatment and prevention of hypercholesterolemia. Early work by Garofalo et al. investigated the use of Pseudomonas pictorum microencapsulated with alginate-polylysine and open pore agar [9]. Microencapsulated $P$. pictorum was shown to have significant cholesterol depletion activity, with the highest activity by the open pore agar microcapsule formulation [9]. Continuing the same type of work, Jones et al. investigated APA microencapsulated genetically modified bile-salt-hydrolase (BSH-) active Lactobacillus plantarum 80 (pCBH1) for its capability to break down and remove bile acids [10]. This research established the use of $\mathrm{BSH}$-active microencapsulated organisms for lowering blood serum cholesterol. Following this work, Martoni et al. demonstrated that APA microencapsulated naturally BSH-active Lactobacillus reuteri can be successfully delivered to the colon and remain enzymatically active, using a simulated human gastrointestinal model [12]. This probiotic formulation can contribute to a significant cholesterol-lowering effect in cardiovascular diseases, by contributing to the deconjugation of bile salts in the intestine [128]. Further research by Jones et al. demonstrated the use of APA microencapsulated BSH-active L. reuteri in a human clinical study, administered as a yogurt formulation [13]. The formulation was shown to reduce low-density lipoprotein (LDL) cholesterol, total cholesterol, apolipoprotein B-100 (apoB-100), and non-high-density lipoprotein (HDL) cholesterol in hypercholesterolemic patients more efficiently than traditional probiotic therapy and other cholesterol-lowering ingredients [13].

Research by Bhathena et al. also investigated the use of APA microencapsulated bacteria, specifically feruloyl esterase (FAE) active L. fermentum, to lower triglyceride and cholesterol levels, major risk factors for coronary artery disease. Research was undertaken with regard to the viability and enzymatic activity of microencapsulated FAE-active $L$. fermentum under simulated gastrointestinal conditions [14, 129]. It was demonstrated that, following gastrointestinal exposure, there was a significant $2.5 \log$ difference in viability between the free and microencapsulated L. fermentum cells [14]. The presence of a higher probiotic viability and FAE activity resulted in significant reductions in serum total cholesterol, LDL cholesterol and serum triglyceride levels in diet-induced hypercholesterolemic hamsters [11]. Similar studies were also performed with microencapsulated $L$. fermentum for the treatment and prevention of metabolic syndrome [15].

4.3. Microencapsulated Lactobacilli in Colon Diseases. Microencapsulated microbes have also gained interest for the modulation of colonic inflammation, specifically with regard to colon cancer, but potentially for other colonic inflammatory disorders, such as inflammatory bowel syndrome (IBS) and inflammatory bowel disease (IBD). Urbanska et al. investigated the antitumorigenic properties of APA microencapsulated Lactobacillus acidophilus in Min (multiple intestinal neoplasia) mice that carry a germline $A p c$ mutation which spontaneously develop numerous pretumoric intestinal neoplasms [16]. Administration of the probiotic led to a significant reduction in the number of adenomas and gastrointestinal neoplasias in the treated animals, suggesting that the microencapsulated bacteria could have a role in the development of a successful colon cancer therapeutic.

Further research investigated the ability of APA microencapsulated L. acidophilus to suppress intestinal inflammation in mice, for potential applications in chronic inflammatory gut diseases such as IBS and IBD [17]. The administration of the microencapsulated formulation led to significant lowering of proinflammatory cytokine levels [17]. Markers linked to colonic epithelial cell survival were also increased by the microencapsulated L. acidophilus formulation [17]. Previously mentioned studies, with regard to FAE-active microencapsulated microbes, have shown significant antioxidant properties, which could also prove beneficial for colon inflammatory disorders $[14,130]$. Research into microencapsulated microorganisms is demonstrating great potential for the treatment and prevention of a number of health disorders, and they are summarized in Table 2.

\section{Microencapsulated Mammalian Cells}

Regenerative medicine is a field focused on the replacement of lost tissue and organs. The delivery of mammalian cells has been proposed to promote the regeneration of organs such as the liver, pancreas, heart, and kidney. Unfortunately, the in vivo delivery of mammalian cells raises a number of challenges. These include (1) immune rejection by the host, (2) a loss in cell survival due to aggregation and impaired nutrition, (3) impaired cellular function due to inadequate gene expression, (4) a requirement for a large amount of readily available cells, and (5) a shortage of human cell donors $[131,132]$. Due to a shortage of human donors, research has turned to nonhuman mammalian cells, but the aforementioned impediments of immune rejection, impaired cellular function, and readily available cells remain present. Microencapsulated cells can provide an alternative approach to resolve the aforementioned obstacles. One of the earliest works in this field was by Bisceglie, in the 1930s, who demonstrated the use of a polymer membrane to encase mouse tumour cells [133]. These were injected in a pig's abdominal cavity and were shown to successfully survive attacks by the host immune system [133]. Since then, a lot of research has been undertaken in this field. This section presents a synopsis of the most significant research with regard to microencapsulation in cell-based therapies, focusing on the applications of diabetes and hepatic disease. 
TABLE 2: Microencapsulated microorganism formulations for therapeutic applications.

\begin{tabular}{|c|c|c|c|c|}
\hline Disease condition & Microcapsule type & Encapsulated cells type & $\begin{array}{l}\text { Delivery method and } \\
\text { models }\end{array}$ & Reference(s) \\
\hline \multirow{9}{*}{ Renal diseases } & APA & E. coli DH5 & In vitro & {$[2]$} \\
\hline & APA & E. coli DH5 & Rat intragastric gavage & {$[2]$} \\
\hline & APA & E. coli DH5 & Rat intramuscular injection & {$[3]$} \\
\hline & Polyvinyl alcohol & E. coli DH5 & In vitro & {$[4]$} \\
\hline & APA & Saccharomyces cerevisiae & Rat intragastric gavage & {$[5]$} \\
\hline & Alginate chitosan alginate & E. coli DH5 & In vitro & {$[6]$} \\
\hline & Alginate chitosan alginate & E. coli DH5 & Rat douche & {$[6]$} \\
\hline & Alginate chitosan & Lactobacillus acidophilus & In vitro & {$[7]$} \\
\hline & APA & Lactobacillus delbrueckii & In vitro & {$[8]$} \\
\hline \multirow{8}{*}{$\begin{array}{l}\text { Cardiovascular } \\
\text { diseases }\end{array}$} & $\begin{array}{l}\text { Alginate and } \\
\text { alginate-polylysine }\end{array}$ & Pseudomonas pictorum & In vitro & {$[9]$} \\
\hline & APA & $\begin{array}{l}\text { Lactobacillus plantarum } 80 \\
\text { (pCBH1) }\end{array}$ & In vitro & {$[10]$} \\
\hline & APA & Lactobacillus fermentum & Hamster intragastric gavage & {$[11]$} \\
\hline & APA & Bifidobacterium longum & In vitro & {$[12]$} \\
\hline & APA & Lactobacillus reuteri & In vitro & {$[12]$} \\
\hline & APA & Lactobacillus reuteri & $\begin{array}{l}\text { Human, incorporated in } \\
\text { yogurt }\end{array}$ & {$[13]$} \\
\hline & APA & Lactobacillus fermentum & In vitro & {$[14]$} \\
\hline & APA & Lactobacillus fermentum & Hamster intragastric gavage & {$[15]$} \\
\hline \multirow{2}{*}{ Colorectal cancer } & APA & Lactobacillus acidophilus & Mouse intragastric gavage & {$[16]$} \\
\hline & Alginate-chitosan & Lactobacillus acidophilus & In vitro & {$[7]$} \\
\hline $\begin{array}{l}\text { Inflammatory bowel } \\
\text { syndrome/ } \\
\text { inflammatory bowel } \\
\text { disease }\end{array}$ & APA & Lactobacillus acidophilus & Mouse intragastric gavage & {$[17]$} \\
\hline \multirow{6}{*}{ Others } & Alginate & Bifidobacterium longum & In vitro & {$[18]$} \\
\hline & Alginate & $\begin{array}{l}\text { Bifidobacterium lactis } \\
\text { Bifidobacterium longum }\end{array}$ & In vitro & {$[19]$} \\
\hline & & Bifidobacterium longum & & \\
\hline & Gelatin & Bifidobacterium bifidum & Rat intragastric gavage & {$[20]$} \\
\hline & & $\begin{array}{l}\text { Bifidobacterium } \\
\text { adolescentis }\end{array}$ & & \\
\hline & $\begin{array}{l}\text { Reconstituted skim milk } \\
\text { with prebiotics }\end{array}$ & Bifidobacterium BB-12 & In vitro & {$[21]$} \\
\hline
\end{tabular}

5.1. Microencapsulated Pancreatic Cells to Treat Diabetes. Type 1 diabetes is a growing concern, with an escalating rate of disease prevalence [134]. With the present lack of a successful therapeutic [134], the delivery of insulin secreting pancreatic islet cells (PICs) has proven promising for the treatment of type 1 diabetes [135]. Unfortunately, the routine use of immunosuppressive drugs to prevent the rejection of implanted PIC predisposes patients to infections and increases the risk of cancer development in the late posttransplant period $[136,137]$. Microencapsulation can act as a barrier, shielding the delivered pancreatic cells from the host's defences, eliminating the need for immunosuppressive drugs. The first study evaluating the morphology and function of encapsulated islet cells was performed by Lim and Sun in 1980 [22]. This research demonstrated that islet cells remained intact morphologically and functionally for 4 months, in vitro. The encapsulated cells were shown to secrete insulin when stimulated with glucose. Further investigations 
by Lim and Sun involved the intraperitoneal transplantation of encapsulated islet cells in streptozotocin-induced diabetic Wistar Lewis rats. The transplanted encapsulated islet cells maintained normoglycemia for 3 weeks [22]. The rats transplanted with nonencapsulated cells had normoglycemia for only 6-8 days, demonstrating the potential of microencapsulation for the treatment of type 1 diabetes.

Studies have investigated the use of microencapsulated PICs to maintain normoglycemia in diabetic animal models. Kobayashi et al. investigated the therapeutic advantage of using encapsulated PIC versus free PIC in the diabetes animal model, nonobese diabetic mice [25]. PICs were encapsulated in $5 \%(\mathrm{w} / \mathrm{w})$ agarose hydrogel and injected directly into the peritoneal cavity and the omental pouch, without any immunosuppressive drug administration [25]. The control group was injected with free PICs [25]. Two weeks following transplantation, the control group was diabetic, as confirmed by intraperitoneal glucose tolerance tests and blood glucose levels [25]. It is to be noted that the free PICs were no longer viable at this time [25]. On the other hand, encapsulated PICs were able to maintain normal blood glucose levels for over 100 days following transplantation [25]. Omer et al. demonstrated similar results with encapsulated porcine neonatal pancreatic cell clusters (NPCCs) capable of differentiating into insulin producing cells when transplanted into streptozotocin-induced diabetic B6AF1 male mice [26]. Microcapsules, containing 12 NPCCs, were manufactured using highly purified alginate cross-linked by barium chloride [26]. The diabetic mice were intraperitoneally transplanted with 10,000 islet equivalent (IE) encapsulated NPCCs in the test group and the equivalent number of nonencapsulated NPCCs in the control group, with no addition of immunosuppressive therapy [26]. The NPCCs were removed 2, 6 and 20 weeks following transplantation [26]. The control group (nonencapsulated NPCCs) remained hyperglycemic while the test group (encapsulated NPCCs) was normoglycemic until the completion of the trial [26]. The function of the transplanted NPCCs was confirmed by the reoccurrence of hyperglycemia following their removal at weeks 2 and 6 [26]. The functionality of the NPCCs was further demonstrated by an insulin upsurge and an improvement in the ratio of $\beta$ cell area to total cellular area at week 20, confirming the differentiation of NPCCs into $\beta$ cells [26]. Like Kobayashi et al., Omer et al. confirmed that microencapsulation successfully provides the encapsulated islet cells with immune protection, without the need for immunosuppression. Moreover, Omer et al. showed the differentiation of NPCCs into insulin producing $\beta$ cells, providing great therapeutic potential for the treatment of type 1 diabetes.

Clinical studies are few, but research by Tuch et al. investigated the transplantation of barium alginate microcapsules containing human islet cells in four type 1 diabetic patients [28]. This group successfully demonstrated the safety of this method, with little C-peptide detected, normal renal function, little cytokine release, and no major infection detected during the trial [28]. Unfortunately, the research group makes the point that the efficacy of the method needs improvement for the therapy to be used clinically, although a decrease in glycemia was observed [28]. Notably, the retrieval of the microcapsules following 16 weeks demonstrated that the encapsulated cells were no longer viable [28].

With respect to future human studies, there is a significant shortage of human insulin secreting cells and so the proposal for xenotransplantation. Xenotransplantation brings about concerns of host immune rejection, an obstacle that microencapsulation could potentially overcome. Abalovich et al. performed a preclinical study investigating the potential of encapsulated pig islet cells for xenotransplantation. Type 1 diabetic dogs were transplanted with encapsulated PICs and demonstrated a significant reduction (20\%-80\%) in insulin necessity after transplantation [27]. Moreover, there was an upsurge of plasma insulin following 6-12 months of transplantation, along with a significant decrease in glycosylated hemoglobin. Thus, Abalovich et al. demonstrated that microencapsulation may be used for xenotransplantation of PICs in humans [27]. Elliott et al. evaluated the function of PIC APA microcapsules in a single type 1 diabetic patient [29]. Following the intraperitoneal implantation of $15,000 \mathrm{IE} / \mathrm{kg}$ bodyweight, at week 12 , insulin requirement levels were decreased by $30 \%$ [29]. The recovery of the microcapsules, following 9.5 years indicated that the PICs were still viable and secreting small levels of insulin [29]. The research by Elliott et al. demonstrates the potential long-term survival of microencapsulated xenogeneic PIC transplanted without the need for immunosuppression [29].

The presented research provides optimism for the future of microencapsulated PICs for the treatment of type 1 diabetes. However, there still is a need for continuing research to demonstrate the cell viability, functionality with respect to insulin secretion, and safety associated with the xenotransplantation and allotransplantations of microencapsulated PICs using long-term clinical studies.

\subsection{Microencapsulated Hepatic Cells to Treat Liver Disease.} Hepatic diseases, including acute liver failure, chronic liver disease, and congenital metabolic liver disease, require the restoration of liver function [138]. Orthotropic liver transplantation is currently the only effective treatment for endstage liver disease [33, 139-142]. However, the shortage of organs, the requirement for immunosuppressive therapy, and the numerous complications associated with liver transplantation limit the overall effectiveness of transplantation [143145]. Recent studies have investigated liver cell transplant (LCT) as a potential therapeutic but, for effective LCT transplantation, immunosuppression is still a requirement [146]. Microencapsulation has been proposed as a method to address these shortcomings, with some important research presented here. The first study evaluating the therapeutic potential of microencapsulated hepatocytes was performed by Sun et al. [31]. Rat hepatocytes, encased in APA microcapsules, were shown to secrete urea and albumin in vitro, two molecules secreted by the normal healthy liver. The encapsulated hepatocytes were transplanted into normal Wistar rats and rats with galactosamine-induced fulminant hepatic failure and still remained viable following 35 days [31]. 
A recent study performed by Teng et al. demonstrated the regeneration of liver cells in $\mathrm{BALB} / \mathrm{C}$ mice with acute liver failure (ALF) by $70 \%$ hepatectomy, using a mixture of microencapsulated rat hepatocytes and human fetal liver stromal cells (FLSCs) supplemented with basal fibroblast growth factor (bFGF) [33]. bFGF was added to increase the metabolic activity of hepatocytes and to promote the self-renewal of human embryonic stem cells [33, 147]. The combined treatment of encapsulated rat hepatocytes, FLSCs, and bFGF enhanced the survival rate by over $86 \%$ when compared to the controls with a significant increase in liver mass following 72 hours [33]. Furthermore, immunohistochemical inspections showed decreased levels of necrotic liver cells with increased levels of proliferating liver cells in the periportal areas [33]. This study concluded that a mixture of encapsulated rat hepatocytes and FLSCs supplemented with bFGF improved the survival of mice with ALF, without the requirement for any immunosuppression [33]. The encapsulated cells were also protected from any host immunoreactions, demonstrating the potential for encapsulated hepatocyte xenotransplantation.

\subsection{Other Applications of Microencapsulated Mammalian} Cells. Considerable research has also been performed using the microencapsulation of mammalian cells for other diseases. An important study, performed by Zhang et al., investigated the use of microencapsulated Chinese hamster ovarian $(\mathrm{CHO})$ cells that secrete vascular endothelial growth factor (VEGF) in Sprague-Dawley rats, as a therapeutic for ischemic heart diseases [36]. The encapsulated cells were shown to be protected from immune rejection, with significantly lower levels of anti-CHO in those rats as compared to the ones administered unencapsulated cells [36]. Following three weeks of transplantation, the encapsulated $\mathrm{CHO}$ cells were found to be functionally active, secreting VEGF [36]. There was also significant improvement in the cardiac function of the rats treated with encapsulated $\mathrm{CHO}$ cells, as demonstrated by a decline in fractional shortening and left ventricular enlargement [36]. This research demonstrates great potential for the use of xenotransplantation for the treatment of ischemic heart disease.

Considerable success has been achieved with microencapsulation in the treatment of other conditions such as severe anemia and neurodegenerative disease and has also found use in parathyroid replacement therapies [40, 41, 97]. Rinsch et al. demonstrated the increase in haematocrit value with immunosuppression for 8 weeks, with the use of encapsulated myoblasts [41]. Likewise, Régulier et al. demonstrated the ability of encapsulated myoblasts to secrete erythropoietin which increased the haematocrit value to over $85 \%$ in anaemic mice for 80 days [42]. Wikström et al. observed viable human retinal pigment epithelial in microcapsules for over 3 months, demonstrating the potential of encapsulation to maintain the viability and functionality of the encased cells [97]. Hasse et al. demonstrated the reduction of daily intake of calcium and vitamin $\mathrm{D}$ by half, in patients suffering from hypocalcaemia by the administration of encapsulated parathyroid tissue particles [40]. Other interesting research demonstrated that microencapsulated retinal pigment epithelial cells can be beneficial for neurodegenerative diseases like Parkinson's [148]. Genetically engineered cells have shown great potential for the development of a cancer therapy, with microencapsulation allowing to bypass the issue of immune rejection [149]. Table 3 provides a comprehensive list of studies where microencapsulated mammalian cells have been used for therapeutic applications.

\section{Microencapsulated Drugs and Other Pharmaceutics}

Microencapsulation technology has greatly enhanced pharmaceutics research in terms of drug delivery devices. This interdisciplinary field comprising polymer science and emulsion technology has not only covered encapsulation of drugs but also of peptides, proteins, and DNA/RNA therapeutic molecules for controlled release studies. This, in turn, has improved the therapeutic efficacy of the molecule with advantages of low dosage requirements and with the ability to be delivered at the targeted site without enzyme degradation by biological fluid proteins. The controlled release of the drug through microspheres/microcapsules occurs via four known mechanisms, namely, diffusion, dissolution, osmosis, and erosion. The phenomenon of sustained controlled release not only protects the drug from degradation but also protects the body from potential toxic effects of the drug [107]. Most of the commonly used polymers for drug applications are poly (lactic acid) (PLA) and poly (lactic-co-glycolic acid) (PLGA) $[90,150]$. Other polysaccharides such as chitosan $[80,151$, $152]$, alginate [153], and lipids [70, 154, 155] have also been explored. The choice of polymer, solvents, stabilizers, and surfactants and the rigidity, integrity, and degradability are important parameters governing the formation of microparticles [98, 156]. As aforementioned, solvent evaporation is accepted by many pharmaceutical industries, and has been used in products already on the market [157]. The microencapsulation methods used also depend on the hydrophilic or hydrophobic properties of the drug or molecule to be encapsulated.

6.1. Microencapsulation of Biological Agents, Food Supplements, Enzymes, and Antibiotics. Biodegradable and biocompatible polymers, such as PLGA, have been used to encapsulate biologically active agents such as risperidone (antipsychotic) [59] and testosterone [60, 158] to form microparticles. Microencapsulation methods have also been developed to deliver an adjuvant or an antigen, encapsulated in PLGA microparticles, as vaccine formulations used for immunization purposes [61, 159]. Likewise, encapsulation of food supplements, such as vitamins and oil substances, has also been performed using emulsion technology [160]. A study, performed by Ratnakar Tandale in 2007, demonstrated the microencapsulation of vitamin $\mathrm{C}$ and gallic acid, as model antioxidants, in whey protein [91]. These antioxidants were encapsulated using spray drying and freeze drying methods. The study determined the highest encapsulation ratio of vitamin $\mathrm{C}$ : whey protein : gallic acid, and the formulations 
TABLE 3: Microencapsulated mammalian cell formulations for therapeutic applications.

\begin{tabular}{|c|c|c|c|c|}
\hline Disease condition & Microcapsule type & Encapsulated cells type & Delivery method and models & Reference(s) \\
\hline \multirow{9}{*}{$\begin{array}{l}\text { Type } 1 \text { diabetes } \\
\text { mellitus }\end{array}$} & Alginate polylysine & Rat PICs & Rat intraperitoneal transplant & {$[22]$} \\
\hline & APA & Rat PICs & Rat intraperitoneal transplant & {$[23]$} \\
\hline & APA & Rat PICs & In vitro & {$[24]$} \\
\hline & Agarose & Mouse PICs & $\begin{array}{l}\text { Mouse intraperitoneal transplant } \\
\text { Directly onto the mouse omentum }\end{array}$ & {$[25]$} \\
\hline & Barium alginate & Porcine NPCCs & Mouse intraperitoneal transplant & {$[26]$} \\
\hline & APA & Porcine PICs & Canine abdominal transplant & {$[27]$} \\
\hline & Barium alginate & Human PICs & Human intraperitoneal transplant & {$[28]$} \\
\hline & APA & Porcine PICs & Human intraperitoneal transplant & {$[29]$} \\
\hline & Alginate poly-L-ornithine & Human PICs & Human intraperitoneal transplant & {$[30]$} \\
\hline \multirow{5}{*}{ Hepatic disease } & APA & Rat hepatocytes & Rat intraperitoneal transplant & {$[31]$} \\
\hline & APA & Rat hepatocytes & Mouse intraperitoneal transplant & {$[32]$} \\
\hline & APA & Rat hepatocytes and human FLSCs & Mouse intraperitoneal transplant & {$[33]$} \\
\hline & APA & Porcine hepatocytes & Mouse intraperitoneal transplant & {$[34]$} \\
\hline & APA & Human umbilical cord blood cells & Rat intraperitoneal transplant & {$[35]$} \\
\hline \multirow{2}{*}{$\begin{array}{l}\text { Cardiovascular } \\
\text { disease }\end{array}$} & APA & $\mathrm{CHO}$ cells & Rat intramyocardial injection & {$[36]$} \\
\hline & APA & Rat mesenchymal stem cells & Rat intramyocardial injection & {$[37]$} \\
\hline \multirow{3}{*}{$\begin{array}{l}\text { Parathyroid } \\
\text { insufficiency }\end{array}$} & Barium alginate & Human parathyroid tissue & Human forearm and leg transplant & {$[38]$} \\
\hline & Barium alginate & Rat parathyroid tissue & Rat paravertebral muscle transplant & {$[39]$} \\
\hline & Barium alginate & Human parathyroid tissue & Human brachioradial muscle & {$[40]$} \\
\hline \multirow{2}{*}{ Anemia } & Polyether-sulfone & Mouse myoblast cells & Mouse dorsal flank transplant & {$[41]$} \\
\hline & Polyether-sulfone & Mouse myoblast cells & Mouse dorsal flank transplant & {$[42]$} \\
\hline \multirow{14}{*}{ Cancer } & Polyether-sulfone & $\begin{array}{l}\text { Human erythroleukemia cells and } \\
\text { mouse melanoma cells }\end{array}$ & $\begin{array}{l}\text { Mouse subcutaneous/extraperitoneal } \\
\text { transplant }\end{array}$ & {$[43]$} \\
\hline & APA & Canine kidney cells & Mouse intraperitoneal injection & {$[44]$} \\
\hline & APA & CHO cells & Mouse intraperitoneal transplant & {$[45]$} \\
\hline & APA & CHO cells & Mouse intraperitoneal injection & {$[46]$} \\
\hline & Alginate polylysine & Porcine aortic endothelial cells & Mouse subcutaneous injection & {$[47]$} \\
\hline & APA & $\begin{array}{l}\text { Genetically modified hamster } \\
\text { kidney cells }\end{array}$ & Mouse subcutaneous injection & {$[48]$} \\
\hline & Alginate-polylysine & $\begin{array}{l}\text { Human genetically engineered fetal } \\
\text { kidney cells }\end{array}$ & Mouse subcutaneous flank injection & {$[49]$} \\
\hline & APA & $\begin{array}{l}\text { Human embryonic genetically } \\
\text { engineered kidney cells }\end{array}$ & Mouse subcutaneous flank injection & {$[50]$} \\
\hline & APA & Mouse myoblasts & Mouse subcutaneous flank injection & {$[51]$} \\
\hline & Alginate & $\begin{array}{l}\text { Human fetal genetically engineered } \\
\text { kidney cells }\end{array}$ & Rat intracerebral implantation & {$[52]$} \\
\hline & APA & $\begin{array}{l}\text { Mouse genetically engineered } \\
\text { myoblasts }\end{array}$ & Mouse intraperitoneal injection & {$[53]$} \\
\hline & Alginate-polylysine & Porcine aortic endothelial cells & Mouse subcutaneous injection & {$[54]$} \\
\hline & Alginate & Genetically engineered CHO cells & Rat intraperitoneal injection & {$[55]$} \\
\hline & APA & $\begin{array}{l}\text { Mouse genetically engineered } \\
\text { myeloma cells }\end{array}$ & Rat subcutaneous injection & {$[56]$} \\
\hline \multirow{2}{*}{$\begin{array}{l}\text { Neurodegenerative } \\
\text { diseases }\end{array}$} & APA & Baby hamster kidney cells & Mouse cerebral cortex implantation & {$[57]$} \\
\hline & Alginate & $\begin{array}{l}\text { Neonatal porcine choroid plexus } \\
\text { cells }\end{array}$ & Rat intracranial transplantation & {$[58]$} \\
\hline
\end{tabular}


were optimized for various storage conditions, such as humidity, temperature, and UV light and dark conditions. [61]. Therapeutic agents such as $\beta$-agonists, anticholinergics, mucolytics, and antimicrobials have also been proposed to be encapsulated for sustained respiratory drug-delivery applications [159]. Haghpanah et al. demonstrated the use of albumin microparticles to deliver salbutamol sulphate as a model drug. This study compared spray drying versus emulsification method of microencapsulation to achieve highest encapsulation efficiency and determined that spray drying achieved $40 \%$ to $60 \%$ of encapsulation efficiency in comparison to emulsification, which yielded $1 \%$ to $2 \%$ encapsulation efficiency [72]. Babtsov et al., demonstrated microencapsulation of protein loaded chitosan nanoparticles by spray drying for pulmonary delivery of drugs [160]. They characterized the microparticles for size and aerodynamic properties. The results showed a protein loading efficiency of $65 \%$ to $80 \%$ with its release of $75 \%$ to $80 \%$ from nanoparticles within 15 minutes. The study also characterized the recovered nanoparticles from microspheres for size and zeta potential and found no change in the values [73].

Other site-specific drug-delivery applications of microencapsulation include the administration of an ester prodrug, tazarotene subconjunctivally or periocularly [161]. In addition, a silica-lipid hybrid (SLH) microcapsule was recently developed by Tan et al. for the oral delivery of poorly water soluble drugs [162]. The SLH microcapsules were shown to provide physicochemical and biopharmaceutical advantages as compared to the unmodified drug, celecoxib, and the commercial Celebrex product [162]. The SLH microcapsules are hypothesized to improve celecoxib absorption due to dissolution enhancement [162]. Antibiotics such as microcycline $\mathrm{HCl}$ have also been administered locally in the periodontal pocket, to modulate inflammation of the periodontium, achieved by embedding the antibiotic-containing microspheres in a strip made of pectin polysaccharide [76, 86]. Another study, by Zheng et al., demonstrated the successful oral delivery of clarithromycin in chitosan-alginateethylcellulose microspheres for the treatment of peptic ulcers caused by Helicobacter pylori [68]. This study explored the biodegradable properties of alginate and chitosan, especially the mucoadhesive property of chitosan, which facilitates the absorption of the bioactive agent across the intestinal mucosa.

6.2. Microencapsulation of Anticancer Drugs and Genes. Microencapsulation has also been used to deliver anticancer agents. A recent study, by Patel et al., demonstrated the advantage of ionotropic gelation to encapsulate a drug, verapamil $\mathrm{HCl}$ in a blend of sodium alginate, hydroxypropyl methylcellulose and hydroxymethylcellulose polymers. The microspheres were characterized for the loading and release kinetics of the drug [77]. Other bioactive molecules such as proteins and DNA/RNA, that are more prone to denaturation, have also been encapsulated by solvent exchange. Likewise, DNA has been encapsulated under reduced shear, to maintain its integrity, for oral delivery applications $[62,82$, 163].
Microcapsules have also been developed from biocompatible but nonbiodegradable synthetic polymers. These can be customized according to the application, to prolong the stability and controlled release of the drug. In view of this, microcapsules have been developed using ethyl cellulose by phase separation to encapsulate highly hydrophilic drugs such as nonsteroidal anti-inflammatory drugs (NSAIDs) and diclofenac sodium, used for the treatment of rheumatoid arthritis and other diseases [78]. A study conducted by Khamanga et al. investigated the use of Eudragit RS100 (ERS) and Eudragit RL 100 (ERL) for microsphere preparation via solvent evaporation, encapsulating losartan potassium as a model drug [79]. The study evaluated the effect of polymer concentration and its type on the amount of drug released. This strategy was followed to encapsulate drugs that impose a delivery challenge due to their low-molecular weight and high hydrophilicity.

6.3. Microencapsulation of Proteins and Hormones. Apart from drug encapsulation and release kinetic studies, microencapsulation technology has also enabled the oral delivery of high-molecular-weight proteins. Due to their highmolecular weight, these molecules are poorly absorbed by the blood stream and are also sensitive to degradation by the acidic environment of the GIT. The sustained release of peptides, proteins, and hormones, such as leutinizing hormone releasing hormone (LHRH) [164-166], recombinant human growth hormone [105], and calcitonin [65] encapsulated in PLGA microcapsules, has been investigated. A study, by Deluca et al., demonstrated the encapsulation of insulin using a blend of acryloyl hydroxyethyl starch (AcHES) hydrogel microparticles with PLGA, an interesting alternative to subcutaneous injection for the management of type 1 diabetes [71]. Another study, involving the encapsulation of insulin, was demonstrated by Caliceti et al. They utilized microspheres prepared using an emulsion technique, comprising a blend of poly(ethylene glycol) with PLA homopolymer and PLG copolymer for a 28-day sustained insulin delivery [167]. Apart from using polymers for microencapsulation techniques, lipids have also been used to encapsulate protein, involving supercritical fluid technology. A study demonstrated the use of this technology using Dynasan 114 and Gelucire 50-02, for the encapsulation of a model protein, bovine serum albumin [87]. All of the previously mentioned applications provided a high therapeutic loading efficiency into the microparticles and provided a sustained release of the active agents $[84,92]$.

As per the literature, microencapsulation techniques, such as spray drying, phase separation, and emulsion techniques, have been extensively used for the encapsulation of drugs and proteins. However, these techniques pose a limitation in pharmaceutical applications, where the therapeutic molecule may degrade due to thermal and chemical exposure involved during the encapsulation process. Moreover, the presence of solvent residues and the polydispersity of the microcapsules account for undesired toxic effects and a lack of optimal loading of the therapeutic. Thus, alternative methods for encapsulation are being explored to avoid such 
TABLE 4: Microencapsulated drugs and other biopharmaceutics.

\begin{tabular}{|c|c|c|c|c|}
\hline Disease condition & Type of microencapsulation & Encapsulated therapeutic & Delivery method and models & Reference(s) \\
\hline \multirow{2}{*}{ Psychosis } & \multirow{2}{*}{$\begin{array}{l}\text { Poly(vinyl alcohol) and } \\
\text { polylactide-co-glycolide }\end{array}$} & 1,2-benzole & \multirow{2}{*}{$\begin{array}{l}\text { Canine intramuscular } \\
\text { injection }\end{array}$} & [59] \\
\hline & & Risperidone & & {$[60]$} \\
\hline \multirow{4}{*}{$\begin{array}{l}\text { Vaccines and gene } \\
\text { therapy }\end{array}$} & Poly(lactic-co-glycolic acid) & MN rgp 120, QS 21 & $\begin{array}{l}\text { Guinea pig subcutaneous } \\
\text { injection }\end{array}$ & {$[61]$} \\
\hline & \multirow{3}{*}{ Poly(D,L-lactide-co-glycolide) } & \multirow{3}{*}{ DNA } & $\begin{array}{l}\text { Mouse intraperitoneal } \\
\text { injection }\end{array}$ & {$[62]$} \\
\hline & & & $\begin{array}{l}\text { Mouse intraperitoneal } \\
\text { injection }\end{array}$ & [63] \\
\hline & & & Mouse intragastric gavage & \\
\hline \multirow{8}{*}{ Hormone therapy } & Poly(lactic-co-glycolic acid) & Norethindrone & Baboon injection & \multirow{3}{*}[60]{} \\
\hline & Poly(lactic-co-glycolic acid) & Estradiol benzoate & Calf base of the ear injection & \\
\hline & D,L-lactide/glycolic copolymer & Testosterone & In vitro & \\
\hline & Poly(lactic-co-glycolic acid) & $\begin{array}{l}\text { Luteinizing hormone releasing } \\
\text { hormone }\end{array}$ & Rat subcutaneous injection & \multirow{3}{*}[64]{} \\
\hline & \multirow[b]{2}{*}{ Poly lactic acid } & Calcitonin & In vitro & \\
\hline & & $\begin{array}{l}\text { Epidermal growth factor } \\
\text { Prolactin }\end{array}$ & Rat subcutaneous injection & \\
\hline & Poly(lactic-co-glycolic acid) & Calcitonin & In vitro & [65] \\
\hline & Ethylcellulose & $\begin{array}{l}\text { Triptorelin acetate } \\
\text { poly(caprolactone) } \\
\text { nanoparticles }\end{array}$ & In vitro & {$[66]$} \\
\hline \multirow{4}{*}{$\begin{array}{l}\text { Gastrointestinal } \\
\text { disorders }\end{array}$} & Chitosan & Cimetidine & In vitro & [67] \\
\hline & Chitosan-alginate-ethylcellulose & Clarithromycin & Rat intragastric gavage & {$[68]$} \\
\hline & Poly(lactic-co-glycolic acid) & Octreotide & In vitro & {$[65]$} \\
\hline & APA & Thalidomide & In vitro & [69] \\
\hline \multirow{3}{*}{ Diabetes } & Glyceryl tripalmitate & \multirow{2}{*}{ Insulin } & Mouse subcutaneous injection & {$[70]$} \\
\hline & Poly lactic acid & & In vitro & {$[64]$} \\
\hline & $\begin{array}{l}\text { Acryloyl hydroxyethyl starch } \\
\text { hydrogel-Poly(lactic-co-glycolic acid) }\end{array}$ & Insulin & Rat subcutaneous injection & {$[71]$} \\
\hline \multirow{5}{*}{$\begin{array}{l}\text { Pulmonary } \\
\text { delivery }\end{array}$} & Albumin & Salbutamol Sulfate & In vitro & {$[72]$} \\
\hline & Lactose-chitosan & & In vitro & \\
\hline & Mannitol-chitosan & Insulin & In vitro & {$[73]$} \\
\hline & Ethyl acetate & Theophylline nanoparticles & In vitro & {$[74]$} \\
\hline & Mannitol & $\begin{array}{l}\text { Insulin-loaded lipid/chitosan } \\
\text { nanoparticles }\end{array}$ & In vitro & {$[75]$} \\
\hline \multirow{6}{*}{ Periodontitis } & \multirow{3}{*}{ Poly lactic acid } & Minocycline $\mathrm{HCl}$ & \multirow{6}{*}{$\begin{array}{l}\text { Canine local administration in } \\
\text { periodontal pockets }\end{array}$} & \multirow{6}{*}[76]{} \\
\hline & & Metronidazole & & \\
\hline & & Dibucaine & & \\
\hline & Poly(l-glutamic acid) & Tetracycline $\mathrm{HCl}$ & & \\
\hline & \multirow{2}{*}{ Poly(lactic-co-glycolic acid) } & Minocycline $\mathrm{HCl}$ & & \\
\hline & & Flurbiprofen & & \\
\hline \multirow{5}{*}{ Hypertension } & Sodium alginate & & & \\
\hline & $\begin{array}{l}\text { Sodium alginate and hydroxypropyl } \\
\text { methylcellulose }\end{array}$ & Verapamil hydrochloride & In vitro & {$[77]$} \\
\hline & $\begin{array}{l}\text { Sodium alginate and hydroxypropyl } \\
\text { cellulose }\end{array}$ & & & \\
\hline & \multirow{2}{*}{ Eudragit RS-Eudragit RL } & Losartan potassium & In vitro & {$[78]$} \\
\hline & & Verapamil and propranolol & In vitro & [79] \\
\hline
\end{tabular}


TABLE 4: Continued.

\begin{tabular}{|c|c|c|c|c|}
\hline Disease condition & Type of microencapsulation & Encapsulated therapeutic & Delivery method and models & Reference(s) \\
\hline \multirow{4}{*}{ Cancer } & \multirow{2}{*}{ Poly lactic acid } & Cisplatin & In vitro & \\
\hline & & Interferon- $\alpha$ & $\begin{array}{l}\text { Mouse intraperitoneal } \\
\text { injection }\end{array}$ & {$[64]$} \\
\hline & Chitosan & Diphtheria toxoid & Mouse intragastric gavage & {$[80]$} \\
\hline & Alginate-chitosan & Oxaliplatin & Mouse intragastric gavage & {$[81]$} \\
\hline \multirow{5}{*}{$\begin{array}{l}\text { Analgesia and } \\
\text { Anesthesia }\end{array}$} & Ethyl cellulose & Diclofenac sodium & In vitro & {$[82]$} \\
\hline & Maltodextrin-whey proteins & Ginger essential oil & In vitro & {$[83]$} \\
\hline & Poly(lactic-co-glycolic acid) & $\begin{array}{l}\text { Ketoprofen } \\
\text { Lidocaine }\end{array}$ & In vitro & [84] \\
\hline & $\begin{array}{l}\text { Poly- } \varepsilon \text {-caprolactone } \\
\text { Ethylcellulose }\end{array}$ & Diclofenac sodium & In vitro & {$[85]$} \\
\hline & Ethylcellulose & $\begin{array}{l}\text { Ibuprofen poly(caprolactone) } \\
\text { nanoparticles }\end{array}$ & In vitro & {$[66]$} \\
\hline \multirow{22}{*}{$\begin{array}{l}\text { Other } \\
\text { applications }\end{array}$} & Poly(lactic-co-glycolic acid) & Bovine serum albumin & In vitro & {$[86]$} \\
\hline & & Tumor necrosis factor & In vitro & \\
\hline & Poly lactic acid & Interleukin-2 & Mouse intravenous injection & {$[64]$} \\
\hline & & Urokinase & In vitro & {$[64]$} \\
\hline & & Panmycin & In vitro & \\
\hline & Trimyristin & & & [87] \\
\hline & Gelucire & Bovine serum albumin (BSA) & In vitro & [8\%] \\
\hline & Chitosan & & & [88] \\
\hline & APA & Carbon nanotubes & In vitro & [89] \\
\hline & Poly lactic acid & Prednisolone & Rat subcutaneous injection & {$[90]$} \\
\hline & \multirow[t]{2}{*}{ Whey protein concentrate } & & \multirow[t]{2}{*}{ In vitro } & [91] \\
\hline & & Gallic acid & & \\
\hline & \multirow{4}{*}{ Poly(lactic-co-glycolic acid) } & Trenbolone acetate & \multirow{7}{*}{ In vitro } & \multirow{7}{*}[60]{} \\
\hline & & Rgp-120 & & \\
\hline & & albumin & & \\
\hline & & Interferon- $\alpha$ & & \\
\hline & \multirow{2}{*}{$\begin{array}{l}\text { Poly(vinyl alcohol) and } \\
\text { polylactide-co-glycolide }\end{array}$} & Ivermectin & & \\
\hline & & Bupivacaine & & \\
\hline & Poly(lactic-co-glycolic acid) & Human growth factor & & \\
\hline & $\begin{array}{l}\text { Acryloyl hydroxyethyl starch } \\
\text { hydrogel-Poly(lactic-co-glycolic acid) }\end{array}$ & $\begin{array}{l}\text { Insulin } \\
\text { Horseradish peroxidase }\end{array}$ & In vitro & {$[71]$} \\
\hline & Glyceryl tripalmitate & Thymocartin & Mouse subcutaneous injection & {$[70]$} \\
\hline & Poly(lactic-co-glycolic acid) & Cyclosporin & In vitro & {$[92]$} \\
\hline
\end{tabular}

limitations. One such study, proposed by Li et al., introduced the use of a high-voltage electrostatic field to encapsulate bovine serum albumin (BSA), a model protein, in sodium alginate microcapsules of $<100 \mu \mathrm{m}$ in size with 80 hours of controlled protein release [88]. This study brought a new dimension for the microencapsulation of protein and peptide-based pharmaceutics.

6.4. Microencapsulation of Nanohybrid Materials. Other applications of microencapsulation involve the encapsulation of nanoparticles, which can offer great advantages in biomedical applications. For example, the microencapsulation of metals with antioxidative effects can be protected from cellular internalization while maintaining their surfacedependent biomimetic properties. In addition, microencapsulation can prevent an initial burst release of therapeutic drugs, an important limitation of many nanoparticle formulations. Hence, microencapsulation of nanoparticles complexing therapeutic molecules has provided an approach for a controlled drug release [74, 85]. A study by Hasan et al. elaborated the use of ibuprofen and triptorelin acetate as the model lipophilic and hydrophilic drugs encapsulated in poly- $\varepsilon$-caprolactone (PCL) nanoparticles, entrapped in microparticles made of ethyl cellulose and ERS. This study revealed a significant reduction in the diffusion of 
drugs across the double-membrane polymeric wall, providing a longer and more controlled therapeutic release [66]. Microencapsulation of nanoparticles can also serve to reduce cytoxicity effects [168]. A recent study, by Li et al., investigated the microencapsulation of nanoemulsions by spray drying, in which Vitamin E acetate was used as a model lipophilic molecule. This technique helped avoid the instability, the aggregation, and the hydrolysis of nanoparticles in suspension [169]. Likewise, a study performed by Lee et al. demonstrated that cationic lipid nanoparticles encapsulating lipophilic drugs could be microencapsulated in an anionic polymeric membrane, forming microcapsules via ionic interactions. This method produced $\mathrm{pH}$-sensitive microbeads, which proved beneficial for the oral delivery of lipophilic drugs [170]. Microencapsulation of polymeric nanoparticles made of chitosan has also been explored for biomedical applications of pulmonary diseases due to their excellent absorption through mucosal surfaces. Protein-loaded lipid/chitosan nanoparticles were encapsulated in microspheres by spray drying, using mannitol as an aerosol excipient $[73,75]$. The produced microspheres showed optimal properties for us in pulmonary diseases. Carbon nanoparticles have also been widely used in biomedical research as a therapeutic vehicle for drugs and genes, specifically with respect to anticancer therapies [171, 172]. A recent study, by Kulamarva et al., investigated the microencapsulation of carbon nanotubes in APA microcapsules for potential oral delivery [89]. The microcapsule membrane has shown resistance against the varying $\mathrm{pH}$ of the gastrointestinal system, thereby protecting the encapsulated therapeutic payload, following a controlled release system and releasing the therapeutic at a targeted location.

It is clear from the work summarized in this paper, that microencapsulation is showing great potential for the delivery of a number of drugs and molecular pharmaceutics. Table 4 summarizes disorders where microencapsulated therapeutic drugs and other agents for the prevention and treatment of health disorders have been investigated.

\section{Challenges and Future Outlooks}

As described in this paper, microencapsulation is a biomedical technology with remarkable therapeutic potential for a wide range of diseases. The process of microencapsulation can be used in designing therapeutic formulations of microbial cells, mammalian cells, drugs, and other molecular pharmaceutics. In addition to the presented applications, other applications are also promising [173-175]. Given the importance of microencapsulation in various disease applications the technology needs to be further enhanced. One aspect that seems critical is targeted delivery using triggered release of the encapsulated contents due to external trigger factors [176-179]. Other uses of microencapsulation that seem promising are the use of this technology in developing disease models, such as models of tumors for developing pharmaceutical formulations $[180,181]$.
It is also clear that, for each microcapsule formulation, the types and physical and chemical properties of the microcapsules must be optimized. Optimization may involve a number of variables, including the type of microencapsulation process, the encapsulation materials used, and the therapeutic loading capacity. Keeping these characteristics in mind, it is also evident that the future success of microencapsulation must look at the optimization of the methods behind the fabrication of microcapsules. Specifically, characteristics such as permeability, mechanical stability, cell viability, controlled release, targeted delivery, drug stability, and shelf-life of the product, including larger-scale industrial production in therapeutically acceptable production environments, need to be optimized for each intended application.

\section{Conflict of Interests}

The authors report no financial or other conflict of interests relevant to the subject of this paper.

\section{Acknowledgments}

The authors would like to acknowledge the Canadian Institute of Health Research (CIHR) Grant (MPO 64308) and grants from Micropharma Limited to Dr. S. Prakash, a Doctoral Alexander Graham Bell Canada Graduate Scholarship from the Natural Sciences and Engineering Research Council of Canada (NSERC) to C. Tomaro-Duchesneau, and a Fonds de la recherché en santé du Québec (FRSQ) Doctoral award to M. Malhotra.

\section{References}

[1] C. Wischke and S. P. Schwendeman, "Principles of encapsulating hydrophobic drugs in PLA/PLGA microparticles," International Journal of Pharmaceutics, vol. 364, no. 2, pp. 298-327, 2008.

[2] S. Prakash and T. M. S. Chang, "In vitro and in vivo uric acid lowering by artificial cells containing microencapsulated genetically engineered E. coli DH5 cells," International Journal of Artificial Organs, vol. 23, no. 7, pp. 429-435, 2000.

[3] S. Prakash and T. M. S. Chang, "Microencapsulated genetically engineered live E. coli $\mathrm{DH} 5$ cells administered orally to maintain normal plasma urea level in uremic rats," Nature Medicine, vol. 2, no. 8, pp. 883-887, 1996.

[4] M. Y. Wang, Y. T. Yu, and T. M. S. Chang, "New method for preparing more stable microcapsules for the entrapment of genetically engineered cells," Artificial Cells, Blood Substitutes, and Immobilization Biotechnology, vol. 33, no. 3, pp. 257-269, 2005.

[5] S. Prakash, R. Coussa, C. Martoni, J. Bhathena, and A. M. Urbanska, "Oral microencapsulated live Saccharomyces cerevisiae cells for use in renal failure uremia: preparation and in vivo analysis," Journal of Biomedicine and Biotechnology, vol. 2010, Article ID 620827, 2010.

[6] J. Lin, W. Yu, X. Liu, H. Xie, W. Wang, and X. Ma, "In Vitro and in vivo characterization of alginate-chitosan-alginate artificial microcapsules for therapeutic oral delivery of live bacterial cells," Journal of Bioscience and Bioengineering, vol. 105, no. 6, pp. 660-665, 2008. 
[7] A. M. Urbanska, J. Bhathena, and S. Prakash, "Live encapsulated Lactobacillus acidophilus cells in yogurt for therapeutic oral delivery: preparation and in vitro analysis of alginate-chitosan microcapsules," Canadian Journal of Physiology and Pharmacology, vol. 85, no. 9, pp. 884-893, 2007.

[8] K. M. Chow, Z. C. Liu, S. Prakash, and T. M. S. Chang, "Free and microencapsulated Lactobacillus and effects of metabolic induction on urea removal," Artificial Cells, Blood Substitutes, and Immobilization Biotechnology, vol. 31, no. 4, pp. 425-434, 2003.

[9] F. A. Garofalo, M. Eng, and T. M. S. Chang, "Immobilization of P. Pictorum in open pore agar, alginate and polylysine-alginate microcapsules for serum cholesterol depletion," Biomaterials, Artificial Cells, and Artificial Organs, vol. 17, no. 3, pp. 271-289, 1989.

[10] M. L. Jones, H. Chen, W. Ouyang, T. Metz, and S. Prakash, "Microencapsulated genetically engineered Lactobacillus plantarum 80 (pCBH1) for bile acid deconjugation and its implication in lowering cholesterol," Journal of Biomedicine and Biotechnology, vol. 2004, no. 1, pp. 61-69, 2004.

[11] J. Bhathena, C. Martoni, A. Kulamarva, A. M. Urbanska, M. Malhotra, and S. Prakash, "Orally delivered microencapsulated live probiotic formulation lowers serum lipids in hypercholesterolemic hamsters," Journal of Medicinal Food, vol. 12, no. 2, pp. 310-319, 2009.

[12] C. Martoni, J. Bhathena, A. M. Urbanska, and S. Prakash, "Microencapsulated bile salt hydrolase producing Lactobacillus reuteri for oral targeted delivery in the gastrointestinal tract," Applied Microbiology and Biotechnology, vol. 81, no. 2, pp. 225-233, 2008.

[13] M. L. Jones, C. J. Martoni, M. Parent, and S. Prakash, "Cholesterol-lowering efficacy of a microencapsulated bile salt hydrolase-active Lactobacillus reuteri NCIMB, 30243 yoghurt formulation in hypercholesterolaemic adults," The British Journal of Nutrition, vol. 107, no. 10, pp. 1505-1513, 2012.

[14] C. Tomaro-Duchesneau, S. Saha, M. Malhotra et al., "Probiotic ferulic acid esterase active Lactobacillus fermentum NCIMB, 5221 APA microcapsules for oral delivery: preparation and in vitro characterization," Pharmaceuticals, vol. 5, no. 2, pp. 236-248, 2012.

[15] J. Bhathena, C. Tomaro-Duchesneau, C. Martoni et al., "Effect of orally administered microencapsulated FA-producing $L$. fermentum on markers of metabolic syndrome: an in vivo analysis," Journal of Diabetes \& Metabolism, vol. 2, article 009, 2012.

[16] A. M. Urbanska, J. Bhathena, C. Martoni, and S. Prakash, "Estimation of the potential antitumor activity of microencapsulated Lactobacillus acidophilus yogurt formulation in the attenuation of tumorigenesis in Apc(Min/+) Mice," Digestive Diseases and Sciences, vol. 54, no. 2, pp. 264-273, 2009.

[17] A. Urbanska, A. Paul, J. Bhathena, and S. Prakash, "Suppression of tumorigenesis: modulation of inflammatory cytokines by oral administration of microencapsulated probiotic yogurt formulation," International Journal of Inflammation, vol. 2010, Article ID 894972, 2010.

[18] K. Y. Lee and T. R. Heo, "Survival of Bifidobacterium longum immobilized in calcium alginate beads in simulated gastric juices and bile salt solution," Applied and Environmental Microbiology, vol. 66, no. 2, pp. 869-873, 2000.

[19] L. T. Hansen, P. M. Allan-Wojtas, Y. L. Jin, and A. T. Paulson, "Survival of Ca-alginate microencapsulated Bifidobacterium spp. in milk and simulated gastrointestinal conditions," Food Microbiology, vol. 19, no. 1, pp. 35-45, 2002.

[20] X. Ruan, H. Shi, G. Xia et al., "Encapsulated Bifidobacteria reduced bacterial translocation in rats following hemorrhagic shock and resuscitation," Nutrition, vol. 23, no. 10, pp. 754-761, 2007.

[21] C. B. Fritzen-Freire, E. S. Prudencio, R. D. M. C. Amboni, S. S. Pinto, A. N. Negrao-Murakami, and F. S. Murakami, "Microencapsulation of bifidobacteria by spray drying in the presence of prebiotics," Food Research International, vol. 45, no. 1, pp. 306-312, 2012.

[22] F. Lim and A. M. Sun, "Microencapsulated islets as bioartifical endocrine pancreas," Science, vol. 210, no. 4472, pp. 908-910, 1980.

[23] G. M. O'Shea, M. F. A. Goosen, and A. M. Sun, "Prolonged survival of transplanted islets of Langerhans encapsulated in a biocompatible membrane," Biochimica et Biophysica Acta, vol. 804, no. 1, pp. 133-136, 1984.

[24] S. Darguy and G. Reach, "Immunoisolation of pancreatic B cells by microencapsulation," Diabetologia, vol. 28 , no. 10, pp. 776-780, 1985.

[25] T. Kobayashi, Y. Aomatsu, H. Iwata et al., "Indefinite islet protection from autoimmune destruction in nonobese diabetic mice by agarose microencapsulation without immunosuppression," Transplantation, vol. 75, no. 5, pp. 619-625, 2003.

[26] A. Omer, V. F. Duvivier-Kali, N. Trivedi, K. Wilmot, S. BonnerWeir, and G. C. Weir, "Survival and maturation of microencapsulated porcine neonatal pancreatic cell clusters transplanted into immunocompetent diabetic mice," Diabetes, vol. 52, no. 1 , pp. 69-75, 2003.

[27] A. G. Abalovich, M. C. Bacqué, D. Grana, and J. Milei, "Pig pancreatic islet transplantation into spontaneously diabetic dogs," Transplantation Proceedings, vol. 41, no. 1, pp. 328-330, 2009.

[28] B. E. Tuch, G. W. Keogh, L. J. Williams et al., "Safety and viability of microencapsulated human islets transplanted into diabetic humans," Diabetes Care, vol. 32, no. 10, pp. 1887-1889, 2009.

[29] R. B. Elliott, L. Escobar, P. L. J. Tan, M. Muzina, S. Zwain, and C. Buchanan, "Live encapsulated porcine islets from a type 1 diabetic patient $9.5 \mathrm{yr}$ after xenotransplantation," Xenotransplantation, vol. 14, no. 2, pp. 157-161, 2007.

[30] R. Calafiore, G. Basta, G. Luca et al., "Standard technical procedures for microencapsulation of human islets for graft into nonimmunosuppressed patients with type 1 diabetes mellitus," Transplantation Proceedings, vol. 38, no. 4, pp. 1156-1157, 2006.

[31] A. M. Sun, Z. Cai, Z. Shi, F. Ma, and G. M. O'Shea, "Microencapsulated hepatocytes: an in vitro and in vivo study," Biomaterials, Artificial Cells, and Artificial Organs, vol. 15, no. 2, pp. 483-496, 1987.

[32] H. Wong and T. M. S. Chang, “The viability and regeneration of artificial cell microencapsulated rat hepatocyte xenograft transplants in mice," Biomaterials, Artificial Cells, and Artificial Organs, vol. 16, no. 4, pp. 731-739, 1988.

[33] Y. Teng, Y. Wang, S. Li et al., “Treatment of acute hepatic failure in mice by transplantation of mixed microencapsulation of rat hepatocytes and transgenic human fetal liver stromal cells," Tissue Engineering Part C, vol. 16, no. 5, pp. 1125-1134, 2010.

[34] J. Mei, A. Sgroi, G. Mai et al., "Improved survival of fulminant liver failure by transplantation of microencapsulated cryopreserved porcine hepatocytes in mice," Cell Transplantation, vol. 18, no. 1, pp. 101-110, 2009. 
[35] F. T. Zhang, H. J. Wan, M. H. Li et al., "Transplantation of microencapsulated umbilical-cord-bloodderived hepaticlike cells for treatment of hepatic failure," World Journal of Gastroenterology, vol. 17, no. 7, pp. 938-945, 2011.

[36] H. Zhang, S. J. Zhu, W. Wang, Y. J. Wei, and S. S. Hu, "Transplantation of microencapsulated genetically modified xenogeneic cells augments angiogenesis and improves heart function," Gene Therapy, vol. 15, no. 1, pp. 40-48, 2008.

[37] A. H. Al Kindi, J. F. Asenjo, Y. Ge et al., "Microencapsulation to reduce mechanical loss of microspheres: implications in myocardial cell therapy," European Journal of Cardio-thoracic Surgery, vol. 39, no. 2, pp. 241-247, 2011.

[38] P. Cabané, P. Gac, J. Amat et al., "Allotransplant of microencapsulated parathyroid tissue in severe postsurgical hypoparathyroidism: a case report," Transplantation Proceedings, vol. 41, no. 9, pp. 3879-3883, 2009.

[39] C. Hasse, J. Schrezenmeir, B. Stinner et al., "Successful allotransplantation of microencapsulated parathyroids in rats," World Journal of Surgery, vol. 18, no. 4, pp. 630-634, 1994.

[40] C. Hasse, G. Klöck, A. Schlosser, U. Zimmermann, and M. Rothmund, "Parathyroid allotransplantation without immunosuppression," The Lancet, vol. 350, no. 9087, pp. 1296-1297, 1997.

[41] C. Rinsch, P. Dupraz, B. L. Schneider et al., "Delivery of erythropoietin by encapsulated myoblasts in a genetic model of severe anemia," Kidney International, vol. 62, no. 4, pp. 1395-1401, 2002.

[42] E. Régulier, B. L. Schneider, N. Déglon, Y. Beuzard, and P. Aebischer, "Continuous delivery of human and mouse erythropoietin in mice by genetically engineered polymer encapsulated myoblasts," Gene Therapy, vol. 5, no. 8, pp. 1014-1022, 1998.

[43] F. Schwenter, S. Zarei, P. Luy et al., "Cell encapsulation technology as a novel strategy for human anti-tumor immunotherapy," Cancer Gene Therapy, vol. 18, no. 8, pp. 553-562, 2011.

[44] G. M. R. Vandenbossche, G. K. De Bruyne, E. A. Bruyneel et al., "Micro-encapsulation of MDCK-ras-e cells prevents loss of E-cadherin invasion-suppressor function in vivo," International Journal of Cancer, vol. 57, no. 1, pp. 73-80, 1994.

[45] H. Teng, Y. Zhang, W. Wang, X. Ma, and J. Fei, "Inhibition of tumor growth in mice by endostatin derived from abdominal transplanted encapsulated cells," Acta Biochimica et Biophysica Sinica, vol. 39, no. 4, pp. 278-284, 2007.

[46] Y. Zhang, W. Wang, Y. Xie et al., "In vivo culture of encapsulated endostatin-secreting Chinese hamster ovary cells for systemic tumor inhibition," Human Gene Therapy, vol. 18, no. 5, pp. 474-481, 2007.

[47] G. Schuch, L. Oliveira-Ferrer, S. Loges et al., "Antiangiogenic treatment with endostatin inhibits progression of AML in vivo," Leukemia, vol. 19, no. 8, pp. 1312-1317, 2005.

[48] T. Joki, M. Machluf, A. Atala et al., "Continuous release of endostatin from microencapsulated engineered cells for tumor therapy," Nature Biotechnology, vol. 19, no. 1, pp. 35-39, 2001.

[49] W. Xu, L. Liu, and I. G. Charles, "Microencapsulated iNOSexpressing cells cause tumor suppression in mice," The FASEB Journal, vol. 16, no. 2, pp. 213-215, 2002.

[50] F. Afkhami, Y. Durocher, and S. Prakash, "Investigation of antiangiogenic tumor therapy potential of microencapsulated HEK293 VEGF ${ }_{165}$ b producing cells," Journal of Biomedicine and Biotechnology, vol. 2010, Article ID 645610, 2010.

[51] P. Cirone, J. M. Bourgeois, and P. L. Chang, "Antiangiogenic cancer therapy with microencapsulated cells," Human Gene Therapy, vol. 14, no. 11, pp. 1065-1077, 2003.
[52] T. A. Read, D. R. Sorensen, R. Mahesparan et al., "Local endostatin treatment of gliomas administered by microencapsulated producer cells," Nature Biotechnology, vol. 19, no. 1, pp. 29-34, 2001.

[53] A. A. Li, F. Shen, T. Zhang, P. Cirone, M. Potter, and P. L. Chang, "Enhancement of myoblast microencapsulation for gene therapy," Journal of Biomedical Materials Research Part B, vol. 77, no. 2, pp. 296-306, 2006.

[54] G. Bartsch, K. Eggert, S. Soker, C. Bokemeyer, R. Hautmann, and G. Schuch, "Combined antiangiogenic therapy is superior to single inhibitors in a model of renal cell carcinoma," Journal of Urology, vol. 179, no. 1, pp. 326-332, 2008.

[55] D. M. Moran, L. G. Koniaris, E. M. Jablonski, P. A. Cahill, C. R. Halberstad, and I. H. McKillop, "Microencapsulation of engineered cells to deliver sustained high circulating levels of interleukin-6 to study hepatocellular carcinoma progression," Cell Transplantation, vol. 15, no. 8-9, pp. 785-798, 2006.

[56] M. Shi, S. Hao, M. Quereshi, X. Guo, C. Zheng, and J. Xiang, "Significant tumor regression induced by microencapsulation of recombinant tumor cells secreting fusion protein," Cancer Biotherapy and Radiopharmaceuticals, vol. 20, no. 3, pp. 260-266, 2005.

[57] G. Orive, R. M. Hernandez, A. Murua et al., "Microencapsulated cells expressing VEGF for the treatment of Alzheimer's disease," pp.S2-S5, 2007.

[58] C. V. Borlongan, S. J. M. Skinner, M. Geaney, A. V. Vasconcellos, R. B. Elliott, and D. F. Emerich, "Intracerebral transplantation of porcine choroid plexus provides structural and functional neuroprotection in a rodent model of stroke," Stroke, vol. 35, no. 9, pp. 2206-2210, 2004.

[59] J. Mesens, M. E. Rickey, and T. J. Atkins, "Microencapsulated 3-piperidinyl-substituted 1,2-benzisoxazoles 1,2-benzisothiazoles," no.US7118763B2, 2006.

[60] J. M. Ramstack, P. F. Herbert, J. Strobel, and T. J. Atkins, "Preparation of biodegradable microparticles containing a biologically active agent," vol. 08725439, no.US5650173A, 1997.

[61] J. L. Cleland, A. Lim, and M. F. Powell, "Methods and compositions for microencapsulation of adjuvants," vol. 460, 363, no.US005643605A, 1997.

[62] D. H. Jones, G. H. Farrar, and J. C. S. Clegg, "Method of making microencapsulated DNA for vaccination and gene therapy," vol. 09079400, no.US06270795B1, 2001.

[63] G. H. Farrar, "Microencapsulated DNA for gene therapy," vol. 99113415.6, no.EP0965336 A1, 1999.

[64] S. H. Hyon and Y. Ikada, "Polylactic acid type microspheres containing physiologically active substance and process for preparing the same," vol. 315, 167, no.US005100669A, 1992.

[65] B. H. Woo, S. H. Dagar, and K. Y. Yang, "Sustained-release microspheres and methods of making and using same," vol. 11/587, 883, no.US20080131513A1, 2008.

[66] A. S. Hasan, M. Socha, A. Lamprecht et al., "Effect of the microencapsulation of nanoparticles on the reduction of burst release," International Journal of Pharmaceutics, vol. 344, no. 12, pp. 53-61, 2007.

[67] L. Illum and H. Ping, "Gastroretentive controlled release microspheres for improved drug delivery," vol. 09/424, 145, no.US006207197B1, 2001.

[68] J. Zheng, C. Liu, D. Bao, Y. Zhao, and X. Ma, "Preparation and evaluation of floating-bioadhesive microparticles containing clarithromycin for the eradication of Helicobacter pylori," Journal of Applied Polymer Science, vol. 102, no. 3, pp. 2226-2232, 2006. 
[69] T. Metz, T. Haque, H. Chen, S. Prakash, D. Amre, and S. Das, "Preparation and in vitro analysis of microcapsule thalidomide formulation for targeted suppression of TNF- $\alpha$," Drug Delivery, vol. 13, no. 5, pp. 331-337, 2006.

[70] H. Reithmeier, J. Herrmann, and A. Göpferich, "Lipid microparticles as a parenteral controlled release device for peptides," Journal of Controlled Release, vol. 73, no. 2-3, pp. 339-350, 2001.

[71] P. Deluca, G. Jiang, and B. Woo, "Poly(Acryloyl-Hydroxyethyl Starch)-PLGA Composition Microspheres," vol.US10549760, no.US20070122487A1, 2007.

[72] M. Haghpanah, C. Marriott, and G. P. Martin, "Potential use of microencapsulation for sustained drug delivery to the respiratory tract," Journal of Aerosol Medicine, vol. 7, no. 2, pp. 185-188, 1994.

[73] A. Grenha, B. Seijo, and C. Remuñán-López, "Microencapsulated chitosan nanoparticles for lung protein delivery," European Journal of Pharmaceutical Sciences, vol. 25, no. 4-5, pp. 427-437, 2005.

[74] M. Jelvehgari, J. Barar, H. Valizadeh, and N. Heidari, "Preparation and evaluation of poly ( $\varepsilon$-caprolactone) nanoparticles-inmicroparticles by W/O/W emulsion method," Iranian Journal of Basic Medical Sciences, vol. 13, no. 3, pp. 85-96, 2010.

[75] A. Grenha, C. Remuñán-López, E. L. S. Carvalho, and B. Seijo, "Microspheres containing lipid/chitosan nanoparticles complexes for pulmonary delivery of therapeutic proteins," European Journal of Pharmaceutics and Biopharmaceutics, vol. 69, no. 1, pp. 83-93, 2008.

[76] J. Y. Lee, M. H. Seo, I. J. Choi, J. H. Kim, and C. M. Pai, "Locally administrable, biodegradable and sustained-release pharmaceutical composition for periodontitis and process for preparation thereof," vol. 09/180, 480, no.US006193994B1, 2001.

[77] H. Patel, R. Patel, and G. Patel, "Ionotropic gelation technique for microencapsulation of antihypertensive drug," Webmed Central Pharmaceutical Sciences, vol. 1, no. 10, pp. 1-10, 2010.

[78] I. Biswal, A. Dinda, D. Das, S. Si, and K. A. Chowdary, "Encapsulation protocol for highly hydrophilic drug using nonbiodegradable polymer," International Journal of Pharmacy and Pharmaceutical Sciences, vol. 3, no. 2, pp. 256-259, 2011.

[79] S. M. Khamanga, N. Parfitt, T. Nyamuzhiwa, H. Haidula, and R. B. Walker, "The evaluation of Eudragit microcapsules manufactured by solvent evaporation using USP Apparatus 1," Dissolution Technologies, vol. 16, no. 2, pp. 15-22, 2009.

[80] Y. Kato, H. Onishi, and Y. Machida, "Application of chitin and chitosan derivatives in the pharmaceutical field," Current Pharmaceutical Biotechnology, vol. 4, no. 5, pp. 303-309, 2003.

[81] A. M. Urbanska, E. D. Karagiannis, G. Guajardo, R. S. Langer, and D. G. Anderson, "Therapeutic effect of orally administered microencapsulated oxaliplatin for colorectal cancer," Biomaterials, vol. 33, no. 18, pp. 4752-4761, 2012.

[82] M. Ahmad, A. Madni, M. Usman, A. Munir, N. Akhtar, and H. M. Shoaib Khan, "Pharmaceutical micro encapsulation technology for development of controlled release drug delivery systems," Proceedings of World Academy of Science, Engineering and Technology, vol. 75, pp. 384-387, 2011.

[83] A. Touré, H. B. Lu, X. Zhang, and X. Xueming, "Microencapsulation of ginger oil in 18DE maltodextrin/whey protein isolate," Journal of Herbs, Spices and Medicinal Plants, vol. 17, no. 2, pp. 183-195, 2011.
[84] W. M. Vaugn, J. E. van Hamont, and J. A. Setterstrom, "Sustained release non-steroidal, anti-inflammatory and lidocaine PLGA microspheres," vol. 08/675, 895, no.US06217911B1, 2001.

[85] M. Jelvehgari, J. Barar, H. Valizadeh, B. Delf Loveymi, and M. Ziapour, "Preparation of diclofenac sodium composite microparticles with improved initial release property," Scientia Iranica, vol. 17, no. 2, pp. 79-89, 2010.

[86] Y. Y. Yang, H. H. Chia, and T. S. Chung, "Effect of preparation temperature on the characteristics and release profiles of PLGA microspheres containing protein fabricated by doubleemulsion solvent extraction/evaporation method," Journal of Controlled Release, vol. 69, no. 1, pp. 81-96, 2000.

[87] I. Ribeiro Dos Santos, J. Richard, B. Pech, C. Thies, and J. P. Benoit, "Microencapsulation of protein particles within lipids using a novel supercritical fluid process," International Journal of Pharmaceutics, vol. 242, no. 1-2, pp. 69-78, 2002.

[88] B. Li, Z. Wujie, and Z. Pan, "A novel method for microencapsulation of protein using high-voltage electrostatic field system," in Proceedings of the American Society of Agricultural and Biological Engineers International (ASABE '06), 2006.

[89] A. Kulamarva, P. M. V. Raja, J. Bhathena et al., "Microcapsule carbon nanotube devices for therapeutic applications," Nanotechnology, vol. 20, no. 2, Article ID 025612, 2009.

[90] A. Smith and I. M. Hunneyball, "Evaluation of poly(lactic acid) as a biodegradable drug delivery system for parenteral administration," International Journal of Pharmaceutics, vol. 30, no. 2-3, pp. 215-220, 1986.

[91] S. Ratnakar Tandale, Microencapsulation of vitamin $C$ and gallic acid in whey protein concentrate by spray and freeze drying-characterization and degradation kinetics [M.S. thesis], 2007.

[92] Z. Ramtoola, "Controlled release biodegradable microand nanospheres containing cyclosporin," vol. 479, 509, no.US005641745A, 1997.

[93] L. Brannon-Peppas, "Controlled release in the food and cosmetics industries," in Polymeric Delivery Systems, chapter 3, pp. 42-52, American Chemical Society, 1993.

[94] P. Aebischer, S. R. Winn, and P. M. Galletti, “Transplantation of neural tissue in polymer capsules," Brain Research, vol. 448, no. 2, pp. 364-368, 1988.

[95] C. K. Colton, "Implantable biohybrid artificial organs," Cell Transplantation, vol. 4, no. 4, pp. 415-436, 1995.

[96] R. Calafiore, "Alginate microcapsules for pancreatic islet cell graft immunoprotection: struggle and progress towards the final cure for type 1 diabetes mellitus," Expert Opinion on Biological Therapy, vol. 3, no. 2, pp. 201-205, 2003.

[97] J. Wikström, M. Elomaa, H. Syväjärvi et al., "Alginate-based microencapsulation of retinal pigment epithelial cell line for cell therapy," Biomaterials, vol. 29, no. 7, pp. 869-876, 2008.

[98] M. Li, O. Rouaud, and D. Poncelet, "Microencapsulation by solvent evaporation: state of the art for process engineering approaches," International Journal of Pharmaceutics, vol. 363, no. 1-2, pp. 26-39, 2008.

[99] T. M. S. Chang, "Semipermeable microcapsules," Science, vol. 146, no. 3643, pp. 524-525, 1964.

[100] E. L. Wittbecker and P. W. Morgan, "Interfacial polycondensation. I, Journal of Polymer Science, vol. 40, no. 137, pp. 289-297, 1959.

[101] R. Arshady, "Preparation of microspheres and microcapsules by interfacial polycondensation techniques," Journal of Microencapsulation, vol. 6, no. 1, pp. 13-28, 1989. 
[102] M. C. Levy, S. Lefebvre, M. Rahmouni, M. C. Andry, and M. Manfait, "Fourier transform infrared spectroscopic studies of human serum albumin microcapsules prepared by interfacial cross-linking with terephthaloylchloride: influence of polycondensation $\mathrm{pH}$ on spectra and relation with microcapsule morphology and size," Journal of Pharmaceutical Sciences, vol. 80, no. 6, pp. 578-585, 1991.

[103] M. C. Levy and M. C. Andry, "Microcapsules prepared through interfacial cross-linking of starch derivatives," International Journal of Pharmaceutics, vol. 62, no. 1, pp. 27-35, 1990.

[104] E. N. Brown, M. R. Kessler, N. R. Sottos, and S. R. White, "In situ poly(urea-formaldehyde) microencapsulation of dicyclopentadiene," Journal of Microencapsulation, vol. 20, no. 6, pp. 719-730, 2003.

[105] H. Mok and T. G. Park, "Water-free microencapsulation of proteins within PLGA microparticles by spray drying using PEGassisted protein solubilization technique in organic solvent," European Journal of Pharmaceutics and Biopharmaceutics, vol. 70, no. 1, pp. 137-144, 2008.

[106] E. Teunou and D. Poncelet, "Batch and continuous fluid bed coating-review and state of the art," Journal of Food Engineering, vol. 53, no. 4, pp. 325-340, 2002.

[107] M. N. Singh, K. S. Y. Hemant, M. Ram, and H. G. Shivakumar, "Microencapsulation: a promising technique for controlled drug delivery," Journal of Research in Pharmaceutical Sciences, vol. 5, no. 2, pp. 65-77, 2010.

[108] R. Dreu, M. Lustrik, M. Perpar, I. Zun, and S. Srcic, "Fluid-bed coater modifications and study of their influence on the coating process of pellets," Drug Development and Industrial Pharmacy, vol. 38, no. 4, pp. 501-511, 2012.

[109] R. Arshady, "Microcapsules for food," Journal of Microencapsulation, vol. 10, no. 4, pp. 413-435, 1993.

[110] Y. Senuma, C. Lowe, Y. Zweifel, J. G. Hilborn, and I. Marison, "Alginate hydrogel microspheres and microcapsules prepared by spinning disk atomization," Biotechnology and Bioengineering, vol. 67, no. 5, pp. 616-622, 2000.

[111] M. Whelehan and I. W. Marison, "Microencapsulation using vibrating technology," Journal of Microencapsulation, vol. 28, no. 8, pp. 669-688, 2012.

[112] P. A. Haas, "Formation of uniform liquid drops by application of vibration to laminar jets," Industrial and Engineering Chemistry Research, vol. 31, no. 3, pp. 959-967, 1992.

[113] J. S. Patil, M. V. Kamalapur, S. C. Marapur, and D. V. Kadam, "Ionotropic gelation and polyelectrolyte complexation: the novel techniques to design hydrogel particulate sustained, modulated drug delivery system: a review," Digest Journal of Nanomaterials and Biostructures, vol. 5, no. 1, pp. 241-248, 2010.

[114] S. Prakash, C. Tomaro-Duchesneau, S. Saha, and A. Cantor, "The gut microbiota and human health with an emphasis on the use of microencapsulated bacterial cells," Journal of Biomedicine and Biotechnology, vol. 2011, Article ID 981214, 12 pages, 2011.

[115] T. Haque, H. Chen, W. Ouyang et al., "Investigation of a new microcapsule membrane combining alginate, chitosan, polyethylene glycol and poly-L-lysine for cell transplantation applications," International Journal of Artificial Organs, vol. 28, no. 6, pp. 631-637, 2005.

[116] H. Chen, W. Ouyang, M. Jones et al., "Preparation and characterization of novel polymeric microcapsules for live cell encapsulation and therapy," Cell Biochemistry and Biophysics, vol. 47, no. 1, pp. 159-168, 2007.
[117] Y. Ogushi, S. Sakai, and K. Kawakami, "Synthesis of enzymatically-gellable carboxymethylcellulose for biomedical applications," Journal of Bioscience and Bioengineering, vol. 104, no. 1, pp. 30-33, 2007.

[118] J. I. Horinaka, K. Kani, Y. Itokawa, E. Ogawa, and Y. Shindo, "Gelation of gellan gum aqueous solutions studied by polarization modulation spectroscopy," Biopolymers, vol. 75, no. 5, pp. 376-383, 2004.

[119] P. L. Madan, "Microencapsulation I. Phase separation or coacervation," Drug Development and Industrial Pharmacy, vol. 4, no. 1, pp. 95-116, 1978.

[120] B. Mohanty and H. B. Bohidar, "Systematic of alcohol-induced simple coacervation in aqueous gelatin solutions," Biomacromolecules, vol. 4, no. 4, pp. 1080-1086, 2003.

[121] S. D. Yeo and E. Kiran, "Formation of polymer particles with supercritical fluids: a review," Journal of Supercritical Fluids, vol. 34, no. 3, pp. 287-308, 2005.

[122] L. Padrela, M. A. Rodrigues, S. P. Velaga, H. A. Matos, and E. G. de Azevedo, "Formation of indomethacin-saccharin cocrystals using supercritical fluid technology," European Journal of Pharmaceutical Sciences, vol. 38, no. 1, pp. 9-17, 2009.

[123] C. Lacroix, F. Grattepanche, Y. Doleyres, and D. Bergmaier, "Immobilised cell technologies for the dairy industry," in Applications of Cell Immobilisation Biotechnology, chapter 18, pp. 295-319, Springer, Amsterdam, The Netherlands, 2005.

[124] B. F. Gibbs, S. Kermasha, I. Alli, and C. N. Mulligan, "Encapsulation in the food industry: a review," International Journal of Food Sciences and Nutrition, vol. 50, no. 3, pp. 213-224, 1999.

[125] FAO and WHO, Health and Nutritional Properties of Probiotics in Food Including Powder Milk with Live Lactic Acid Bacteria, 2001.

[126] S. Prakash and T. M. S. Chang, "Preparation and in vitro analysis of microencapsulated genetically engineered $E$. coli DH5 cells for urea and ammonia removal," Biotechnology and Bioengineering, vol. 46, no. 6, pp. 621-626, 1995.

[127] H. Gao, Y. Yu, B. Cai, and M. Wang, "Preparation and properties of microencapsulated genetically engineered bacteria cells for oral therapy of uremia," Chinese Science Bulletin, vol. 49, no. 11, pp. 1117-1121, 2004.

[128] J. W. Anderson and S. E. Gilliland, "Effect of fermented milk (yogurt) containing Lactobacillus acidophilus L1 on serum cholesterol in hypercholesterolemic humans," Journal of the American College of Nutrition, vol. 18, no. 1, pp. 43-50, 1999.

[129] J. Bhathena, A. Kulamarva, C. Martoni, A. M. Urbanska, and S. Prakash, "Preparation and in vitro analysis of microencapsulated live Lactobacillus fermentum 11976 for augmentation of feruloyl esterase in the gastrointestinal tract," Biotechnology and Applied Biochemistry, vol. 50, no. 1, pp. 1-9, 2008.

[130] C. Tomaro-Duchesneau, S. Saha, M. Malhotra et al., "Lactobacillus fermentum NCIMB, 5221 has a greater ferulic acid production compared to other ferulic acid esterase producing Lactobacilli," International Journal of Probiotics and Prebiotics, vol. 7, no. 1, pp. 23-32, 2012.

[131] Y. Teramura and H. Iwata, "Bioartificial pancreas. Microencapsulation and conformal coating of islet of Langerhans," Advanced Drug Delivery Reviews, vol. 62, no. 7-8, pp. 827-840, 2010.

[132] K. J. Scanlon, "Cancer gene therapy: challenges and opportunities," Anticancer Research, vol. 24, no. 2, pp. 501-504, 2004.

[133] V. Bisceglie, "Uber die antineoplastische immunitat: heterologe Einpflanzung von Tumoren in Huhner-embryonen," Zeitschrift für Krebsforschung, vol. 40, no. 1, pp. 122-140, 1933. 
[134] T. L. Van Belle, K. T. Coppieters, and M. G. Von Herrath, “Type 1 diabetes: etiology, immunology, and therapeutic strategies," Physiological Reviews, vol. 91, no. 1, pp. 79-118, 2011.

[135] A. M. J. Shapiro, J. R. T. Lakey, E. A. Ryan et al., "Islet transplantation in seven patients with type 1 diabetes mellitus using a glucocorticoid-free immunosuppressive regimen," New England Journal of Medicine, vol. 343, no. 4, pp. 230-238, 2000.

[136] B. L. Kasiske, H. A. Chakkera, T. A. Louis, and J. Z. Ma, "A meta-analysis of immunosuppression withdrawal trials in renal transplantation," Journal of the American Society of Nephrology, vol. 11, no. 10, pp. 1910-1917, 2000.

[137] M. T. Van Leeuwen, A. E. Grulich, S. P. McDonald et al., "Immunosuppression and other risk factors for lip cancer after kidney transplantation," Cancer Epidemiology Biomarkers and Prevention, vol. 18, no. 2, pp. 561-569, 2009.

[138] V. Dixit, R. Darvasi, M. Arthur, M. Brezina, K. Lewin, and G. Gitnick, "Restoration of liver function in Gunn rats without immunosuppression using transplanted microencapsulated hepatocytes," Hepatology, vol. 12, no. 6, pp. 1342-1349, 1990.

[139] W. M. Lee, R. H. Squires, S. L. Nyberg, E. Doo, and J. H. Hoofnagle, "Acute liver failure: summary of a workshop," Hepatology, vol. 47, no. 4, pp. 1401-1415, 2008.

[140] W. Bernal, G. Auzinger, A. Dhawan, and J. Wendon, "Acute liver failure," The Lancet, vol. 376, no. 9736, pp. 190-201, 2010.

[141] D. Van Poll, Y. Nahmias, A. Soto-Gutierrez et al., "Human immune reactivity against liver sinusoidal endothelial cells from GalT $\alpha(1,3)$ GalT-deficient pigs," Cell Transplantation, vol. 19, no. 6-7, pp. 783-789, 2010.

[142] J. C. Gerlach, K. Zeilinger, and J. F. Patzer, "Bioartificial liver systems: why, what, whither?" Regenerative Medicine, vol. 3, no. 4, pp. 575-595, 2008.

[143] G. M. Abouna, "Organ shortage crisis: problems and possible solutions," Transplantation Proceedings, vol. 40, no. 1, pp. 34-38, 2008.

[144] M. Vivarelli, A. Dazzi, M. Zanello et al., "Effect of different immunosuppressive schedules on recurrence-free survival after liver transplantation for hepatocellular carcinoma," Transplantation, vol. 89, no. 2, pp. 227-231, 2010.

[145] J. P. Duffy, J. C. Hong, D. G. Farmer et al., "Vascular complications of orthotopic liver transplantation: experience in more than 4,200 patients," Journal of the American College of Surgeons, vol. 208, no. 5, pp. 896-903, 2009.

[146] F. Smets, M. Najimi, and E. M. Sokal, "Cell transplantation in the treatment of liver diseases," Pediatric Transplantation, vol. 12, no. 1, pp. 6-13, 2008.

[147] J. Xi, Y. Wang, P. Zhang et al., "Human fetal liver stromal cells that overexpress bFGF support growth and maintenance of human embryonic stem cells," PLoS ONE, vol. 5, no. 12, Article ID e14457, 2010.

[148] B. S. McKay, B. Goodman, T. Falk, and S. J. Sherman, "Retinal pigment epithelial cell transplantation could provide trophic support in Parkinson's disease: results from an in vitro model system," Experimental Neurology, vol. 201, no. 1, pp. 234-243, 2006.

[149] J. M. Löhr, R. Saller, B. Salmons, and W. H. Günzburg, "Microencapsulation of genetically engineered cells for cancer therapy," Methods in Enzymology, vol. 346, article 35, pp. 603-618, 2002.

[150] J. M. Anderson and M. S. Shive, "Biodegradation and biocompatibility of PLA and PLGA microspheres," Advanced Drug Delivery Reviews, vol. 28, no. 1, pp. 5-24, 1997.
[151] J. Garces Garces, “Microcapsules,” no. US6818296B1, 2004.

[152] L. Illum and H. Ping, "Gastroretentive controlled release microspheres for improved drug delivery," vol. 09424145, no. US6207197B1, 2001.

[153] O. Smidsrod and G. Skjak-Braek, "Alginate as immobilization matrix for cells," Trends in Biotechnology, vol. 8, no. 3, pp. 71-78, 1990.

[154] K. Westesen and B. Siekmann, "Solid lipid particles, particles of bioactive agents and methods for the manufacture and use thereof," vol. 757, 276, no. US005885486A, 1999.

[155] M. R. Gasco, "Pharmaceutical composition in form of solid lipidic microparticles suitable to parenteral administration," vol.EP19980929383, no.EP0988031, 2003.

[156] D. Poncelet, "Microencapsulation: fundamentals, methods and applications," in Surface Chemistry in Biomedical and Environmental Science, pp. 23-34, Springer, Amsterdam, The Netherlands, 2006.

[157] W. M. Obeidat, "Recent patents review in microencapsulation of pharmaceuticals using the emulsion solvent removal methods," Recent Patents on Drug Delivery and Formulation, vol. 3, no. 3, pp. 178-192, 2009.

[158] M. E. Rickey, "Preparation of biodegradable, biocompatible microparticles containing a biologically active agent," vol. 9/578717, no.US6290983, 2001.

[159] R. H. Reid, J. E. van Hamont, W. R. Brown, E. C. Boedeker, and C. Thies, "Microparticle carriers of maximal uptake capacity by both M cells and non-M cells," vol. 242, 960, no.US005693343A, 1997.

[160] V. Babtsov, Y. Shapiro, and E. Kvitnitsky, "Method of microencapsulation," vol. 10, 130, 529, no.US6932984, 2005.

[161] P. M. Hughes and C. Olejnik, "Delivery of a drug via subconjunctival or periocular delivery of a prodrug in a polymeric microparticle," vol. 20040777796, no.EP1644047, 2006.

[162] A. Tan, S. Simovic, A. K. Davey, T. Rades, and C. A. Prestidge, "Silica-lipid hybrid (SLH) microcapsules: a novel oral delivery system for poorly soluble drugs," Journal of Controlled Release, vol. 134, no. 1, pp. 62-70, 2009.

[163] G. H. Farrar, A. M. Tinsley-Bown, and D. H. Jones, "Encapsulation of bioactive agents," vol. 09/310, 936, no.US6309569, 2003.

[164] S. Kamei, M. Yamada, and Y. Ogawa, "Method of producing sustained-release microcapsules," vol. 562, 634, no.US005575987A, 1996.

[165] W. Wang, X. Liu, Y. Xie et al., "Microencapsulation using natural polysaccharides for drug delivery and cell implantation," Journal of Materials Chemistry, vol. 16, no. 32, pp. 3252-3267, 2006.

[166] S. Kamei, Y. Igari, and Y. Ogawa, "Sustained-release preparation," vol. 10/127, 558, no.US007048947B2, 2006.

[167] P. Caliceti, S. Salmaso, N. Elvassore, and A. Bertucco, "Effective protein release from PEG/PLA nano-particles produced by compressed gas anti-solvent precipitation techniques," Journal of Controlled Release, vol. 94, no. 1, pp. 195-205, 2004.

[168] A. Romoser, D. Ritter, R. Majitha, K. E. Meissner, M. McShane, and C. M. Sayes, "Mitigation of quantum dot cytotoxicity by microencapsulation," PLoS ONE, vol. 6, no. 7, Article ID e22079, 2011.

[169] X. Li, N. Anton, T. M. Ta, M. Zhao, N. Messaddeq, and T. F. Vandamme, "Microencapsulation of nanoemulsions: novel Trojan particles for bioactive lipid molecule delivery," International Journal of Nanomedicine, vol. 6, no. 1, pp. 1313-1325, 2011. 
[170] K. E. Lee, S. H. Cho, H. B. Lee, S. Y. Jeong, and S. H. Yuk, "Microencapsulation of lipid nanoparticles containing lipophilic drug," Journal of Microencapsulation, vol. 20, no. 4, pp. 489-496, 2003.

[171] S. Prakash, M. Malhotra, W. Shao, C. Tomaro-Duchesneau, and S. Abbasi, "Polymeric nanohybrids and functionalized carbon nanotubes as drug delivery carriers for cancer therapy," Advanced Drug Delivery Reviews, vol. 63, no. 14-15, pp. 1340-1351, 2011.

[172] S. Prakash and A. G. Kulamarva, "Recent advances in drug delivery: potential and limitations of carbon nanotubes," Recent Patents on Drug Delivery \& Formulation, vol. 1, no. 3, pp. 214-221, 2007.

[173] E. I. Paramera, S. J. Konteles, and V. T. Karathanos, "Microencapsulation of curcumin in cells of Saccharomyces cerevisiae," Food Chemistry, vol. 125, no. 3, pp. 892-902, 2011.

[174] G. Shi, L. Rao, H. Yu, H. Xiang, H. Yang, and R. Ji, "Stabilization and encapsulation of photosensitive resveratrol within yeast cell," International Journal of Pharmaceutics, vol. 349, no. 1-2, pp. 83-93, 2008.

[175] J. R. P. Bishop, G. Nelson, and J. Lamb, "Microencapsulation in yeast cells," Journal of Microencapsulation, vol. 15, no. 6, pp. 761-773, 1998.

[176] S. A. Hamad, S. D. Stoyanov, and V. N. Paunov, "Triggered cell release from shellac-cell composite microcapsules," Soft Matter, vol. 8, no. 1, pp. 5069-5077, 2012.

[177] A. P. Esser-Kahn, N. R. Sottos, S. R. White, and J. S. Moore, "Programmable microcapsules from self-immolative polymers," Journal of the American Chemical Society, vol. 132, no. 30, pp. 10266-10268, 2010.

[178] M. H. Lee, K. C. Hribar, T. Brugarolas, N. P. Kamat, J. A. Burdick, and D. Lee, "Harnessing interfacial phenomena to program the release properties of hollow microcapsules," Advanced Functional Materials, vol. 22, no. 1, pp. 131-138, 2012.

[179] L. Gao, J. Fei, J. Zhao, W. Cui, Y. Cui, and J. Li, "pH- and redoxresponsive polysaccharide-based microcapsules with autofluorescence for biomedical applications," Chemistry, vol. 18, no. 11, pp. 3185-3192, 2012.

[180] M. Z. Ma, D. F. Cheng, J. H. Ye et al., "Microencapsulated tumor assay: evaluation of the nude mouse model of pancreatic cancer," World Journal of Gastroenterology, vol. 18, no. 3, pp. 257-267, 2012.

[181] D. S. Zaytseva-Zotova, O. O. Udartseva, E. R. Andreeva et al., "Polyelectrolyte microcapsules with entrapped multicellular tumor spheroids as a novel tool to study the effects of photodynamic therapy," Journal of Biomedical Materials Research Part B, vol. 97, no. 2, pp. 255-262, 2011. 

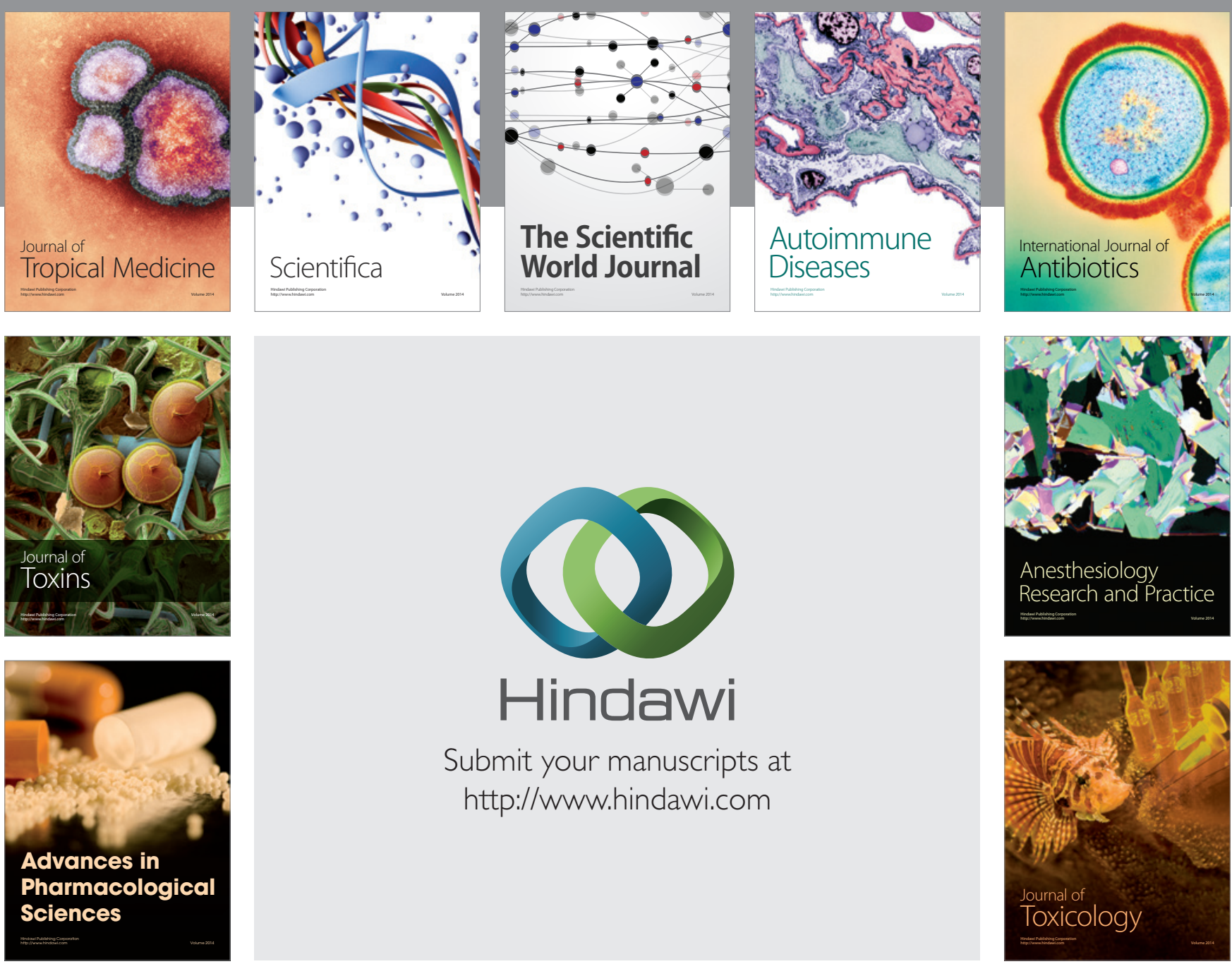

\section{Hindawi}

Submit your manuscripts at

http://www.hindawi.com
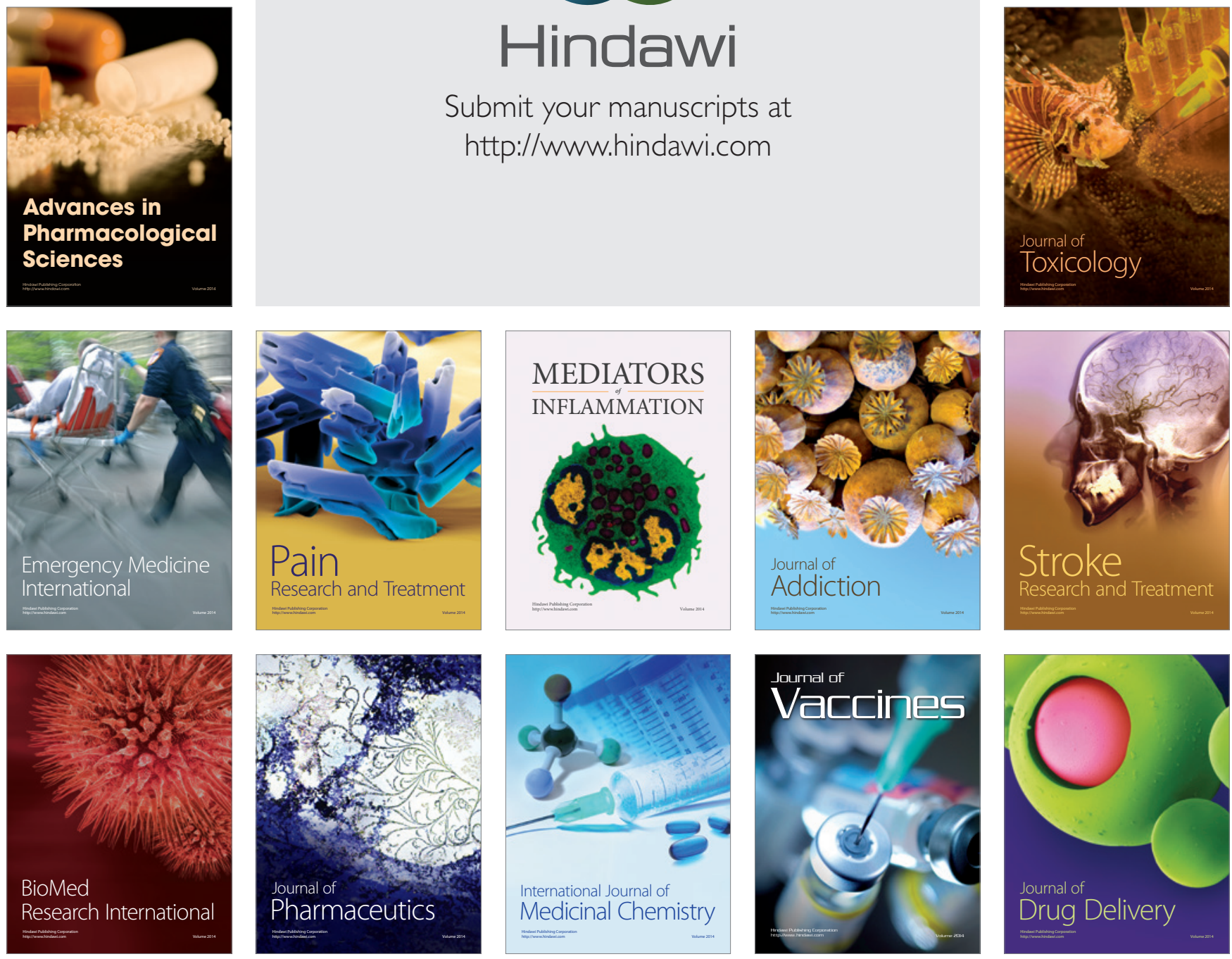